\title{
Impact of vegetation on the simulation of seasonal monsoon rainfall over the Indian subcontinent using a regional model
}

\author{
Surya K Dutta ${ }^{1}$, Someshwar Das ${ }^{1, *}, \mathrm{~S} \mathrm{C} \mathrm{Kar}^{1}$, U C Mohanty ${ }^{2}$ and P C Joshi ${ }^{3}$ \\ ${ }^{1}$ National Centre for Medium Range Weather Forecasting, Noida, UP 201 307, India. \\ ${ }^{2}$ Centre for Atmospheric Science, IIT, Delhi, India. \\ ${ }^{3}$ Space Application Centre, ISRO, Ahmedabad 380 015, India. \\ *e-mail: somesh07@yahoo.com_somesh03@gmail.com
}

The change in the type of vegetation fraction can induce major changes in the local effects such as local evaporation, surface radiation, etc., that in turn induces changes in the model simulated outputs. The present study deals with the effects of vegetation in climate modeling over the Indian region using the MM5 mesoscale model. The main objective of the present study is to investigate the impact of vegetation dataset derived from SPOT satellite by ISRO (Indian Space Research Organization) versus that of USGS (United States Geological Survey) vegetation dataset on the simulation of the Indian summer monsoon. The present study has been conducted for five monsoon seasons (1998-2002), giving emphasis over the two contrasting southwest monsoon seasons of 1998 (normal) and 2002 (deficient).

The study reveals mixed results on the impact of vegetation datasets generated by ISRO and USGS on the simulations of the monsoon. Results indicate that the ISRO data has a positive impact on the simulations of the monsoon over northeastern India and along the western coast. The MM5USGS has greater tendency of overestimation of rainfall. It has higher standard deviation indicating that it induces a dispersive effect on the rainfall simulation. Among the five years of study, it is seen that the RMSE of July and JJAS (June-July-August-September) for All India Rainfall is mostly lower for MM5-ISRO. Also, the bias of July and JJAS rainfall is mostly closer to unity for MM5-ISRO. The wind fields at $850 \mathrm{hPa}$ and $200 \mathrm{hPa}$ are also better simulated by MM5 using ISRO vegetation. The synoptic features like Somali jet and Tibetan anticyclone are simulated closer to the verification analysis by ISRO vegetation. The $2 \mathrm{~m}$ air temperature is also better simulated by ISRO vegetation over the northeastern India, showing greater spatial variability over the region. However, the JJAS total rainfall over north India and Deccan coast is better simulated using the USGS vegetation. Sensible heat flux over north-west India is also better simulated by MM5-USGS.

\section{Introduction}

Various land surface features, viz., vegetation and soil types, soil moisture, snow cover, land-sea contrast, inland water bodies, etc., at various temporal and spatial scales greatly influence the regional climate system (Betts et al 1996; Sellers et al 1996; Baldi et al 2008). For any weather system to develop and sustain over land, the contribution of the land surface is of primary concern. Land surface functions as both source and sink for the atmospheric enthalpy and moisture, by absorbing and releasing the solar radiation in different forms. Partitioning of net solar radiation received at the surface into sensible, latent and ground heat fluxes by the land surface modulates the soil wetness

Keywords. Vegetation; monsoon; rainfall; mesoscale; simulation; forecast; TRMM. 
condition, which in turn acts as a modulator of low frequency variability in the climate. After the sea surface temperature, soil moisture and snow cover are regarded as the most important 'memory mechanisms' for time scales ranging from weeks to seasons. Different feedback processes (both positive and negative) from the land surface is an important contributing aspect of climate change and variability and has a strong influence over the various cycles operating between the land and the atmosphere (Lim et al 2008; Oleson et al 2008; Vinodkumar et al 2008). Thus, the surface weather variables such as, surface air temperature, surface humidity and wind speed at the surface are largely influenced and determined by the surface energy fluxes; the same for the low-level cloudiness and precipitation, but to a lower extent.

Previously, several studies have been made to investigate the role of land surface processes and the mechanisms that govern land-atmosphere interactions in the monsoon systems (e.g., Meehl 1994; Liu and Wu 1997; Webstar et al 1998; Zeng et al 1998; Sun et al 2001; Wu et al 2002). Lau and Bua (1998) and Yang and Lau (1998) have found that the land surface had substantial but limited effects at local scales. Simulations using two different land surface schemes; one with and the other without explicit vegetation parameterization but same surface albedo, produces substantial differences at regional scales, especially in the monsoon regions and some of the large continental areas (Xue et al 2004).

Detailed investigation have been made through GCM simulations to study the effect of changes in vegetation feedback into the climate over South America (e.g., Lean and Warrilow 1989; Norbe et al 1991; Hoffmann and Jackson 2000), tropical Africa (e.g., Xue 1997; Zeng and Neelin 2000), and tropical Asia (Mabuchi et al 2005). It has been seen that inclusion of the satellite derived vegetation indices and sea surface temperature (SST) produces better seasonal and inter-annual precipitation variations than the experiment with SST but no inter-annual variations in fractional vegetation cover and leaf area index (Weiping et al 2005). Using a quasi-equilibrium tropical circulation model coupled with a simple land model, Zeng et al (1999) demonstrated that interactive vegetation enhances the decadal variability of Sahel rainfall. In some recent studies using regional circulation models over North China it was found that increased vegetation cover showed lowering of surface temperature, enhancement of precipitation and also, lowering of surface runoff ( $\mathrm{Lu}$ and Chen 1999; Zheng et al 2002).

Over Indian region, the vegetation type and soil moisture undergoes rapid and significant variations specially, during the southwest monsoon period.
Also, India has a very diverse and complex topography throughout, influencing the climatic variation over varied temporal and spatial scales. In view of this and because of the importance of the land surface forcing, the accuracy of land-use information is important to obtain accurate simulations. The change in the type of vegetation fraction can induce major changes in the local effects such as local evaporation, surface radiation, etc., that in turn induces changes in the model simulated outputs. It is also seen that the monsoon precipitation and land surface temperature over the Indian subcontinent landmass, in turn have, significant impact on the distribution of vegetation (Sarkar et al 2004). Different vegetation types with varied spatial coverage have a marked influence on precipitation patterns, whose effects have also been observed on the forecast models (Kar 1990). Xue et al (1996) through a series of experiments have revealed that land surface effects on the atmospheric variables at and near the surface during the North American summer are very pronounced and persistent, but are limited to the area of the anomalous land surface forcing.

The present study deals with regional climate modeling, i.e., regarding summer monsoon rainfall over the Indian region. An attempt has been made to see the influence of vegetation over the Indian monsoon rainfall as simulated by the model. The main objective of the present study is the comparison of ISRO generated vegetation with that of USGS, i.e., to detect the superior quality vegetation data over the Indian region. Section 2 presents the methodology, the model used, time and domain of study and data used. Results are discussed in section 3 and finally conclusions are given in section 4 .

\section{Methodology}

\subsection{Model description}

The non-hydrostatic version of the MM5 modeling system developed at Penn State University/ National Centre for Atmospheric Research (PSU/ NCAR) has been used for this study (Grell et al 1994). It is a limited area, non-hydrostatic model with vertical levels as the terrain following sigma co-ordinate. It has been designed to simulate both mesoscale and regional-scale atmospheric circulations. The model preprocessor was modified to read the National Centre for Medium Range Weather Forecasting (NCMRWF) global model (T80L18) output to prepare the initial and boundary conditions for the MM5 model which are, updated every 12 hours. The model has been integrated based on the initial conditions at 00GMT of 16 May for the 
Table 1. Configuration of MM5 (Version 3.6) used for this study.

\begin{tabular}{lll}
\hline Model elements & \multicolumn{1}{c}{ Components } & \multicolumn{1}{c}{ Specifications } \\
\hline Domain & Horizontal & Outer domain-1 $(90 \mathrm{~km})$ \\
& Vertical & Inner domain-2 $(30 \mathrm{~km})$ \\
& Time steps & Staggered Arakawa B-grid \\
Topography & 23 Sigma levels \\
& Vegetation/land use & Domain-1: 270 s, domain-2: $90 \mathrm{~s}$ \\
& & USGS \\
& & USGS \& ISRO \\
Dynamics & Time integration & Non-hydrostatic \\
& Boundary conditions & Two-way nesting \\
& Semi-implicit \\
& Horizontal diffusion & Fixed \\
& & Time-dependent/nest \\
Physics & Fourth order for inner domain \\
& Cumulus parameterization & Second order for the coarser domain \\
& PBL parameterization & MRF PBL \\
& Explicit moisture schemes & Simple ice \\
Radiation scheme & Cloud-radiation interaction \\
Land surface processes & Five layer soil model \\
\hline
\end{tabular}

years 1998-2002. Starting from the date, the simulation has been carried forward for all the four months of Southwest Monsoon Season, till 00GMT of 10 October for all the five years (1998-2002). The configuration of the mesoscale model used for the present study is described in table 1 .

T80L18 (triangular truncation at wave number 80 with 18 vertical layers) is the global spectral model (originally adapted from NCEP - National Centre for Environmental Prediction) and is used as the forecast model at NCMRWF. It has horizontal resolution of T80 waves and 18 sigma layers in the vertical. The model has been modified and improved for use in a Seasonal Prediction System. Details of the model may be found at Kanamitsu et al (1991). Further improvements to the model are described in John and Begum (1997), Basu et al (2002) and Kar et al (2002). Kar (2007) have used NCEP Reanalysis-II data as the initial conditions along with observed Reynolds SST for seasonal simulation of Indian Summer Monsoon. For the present study, the MM5 model has been integrated for the whole monsoon season (June, July, August and September) based on the boundary condition obtained from the seasonal simulation of Kar (2007).

\subsection{Experimental setup}

The MM5 model (version 3.6) has been simulated for 138 days starting from 00GMT of 16 May to 00GMT of 1 October, for all the five years from 1998-2002. Initial and boundary conditions for the mesoscale model are prepared from the NCMRWF global model T80L18. The 138 days integrations are done based on the initial condition at 00GMT of 16 May for each year. The boundary conditions from the global model are updated every 12 hours. In recent years, many investigators have used such models for downscaling seasonal forecasting and climate applications (Nobre et al 2001; Rao et al 2004; Leung et al 2006). The simulations for all the five years (1998-2002) have been done separately using both the vegetation fractions, ISRO and USGS. The simulated outputs so obtained were compared with the observational dataset.

\subsection{Period of study}

For the present study, five consecutive (1998-2002) Indian southwest monsoon season has been chosen. Year 1998 has been regarded as a normal southwest monsoon season in terms of rainfall and year 2002 was a deficient monsoon season, especially the rainfall during the month of July was deficient. For the years 1999-2001 India had normal monsoon. For brevity, the discussions are mostly concentrated over the two contrasting monsoon seasons 1998 and 2002.

In 1998, the seasonal rainfall was excess in 12 and normal in 21 meteorological sub-divisions. It was deficient in only two meteorological sub-divisions namely Orissa $(-25 \%)$ and east Madhya Pradesh $(-27 \%)$. Seasonal total rainfall for the country as a whole was normal and received $105 \%$ of its long period average value. 


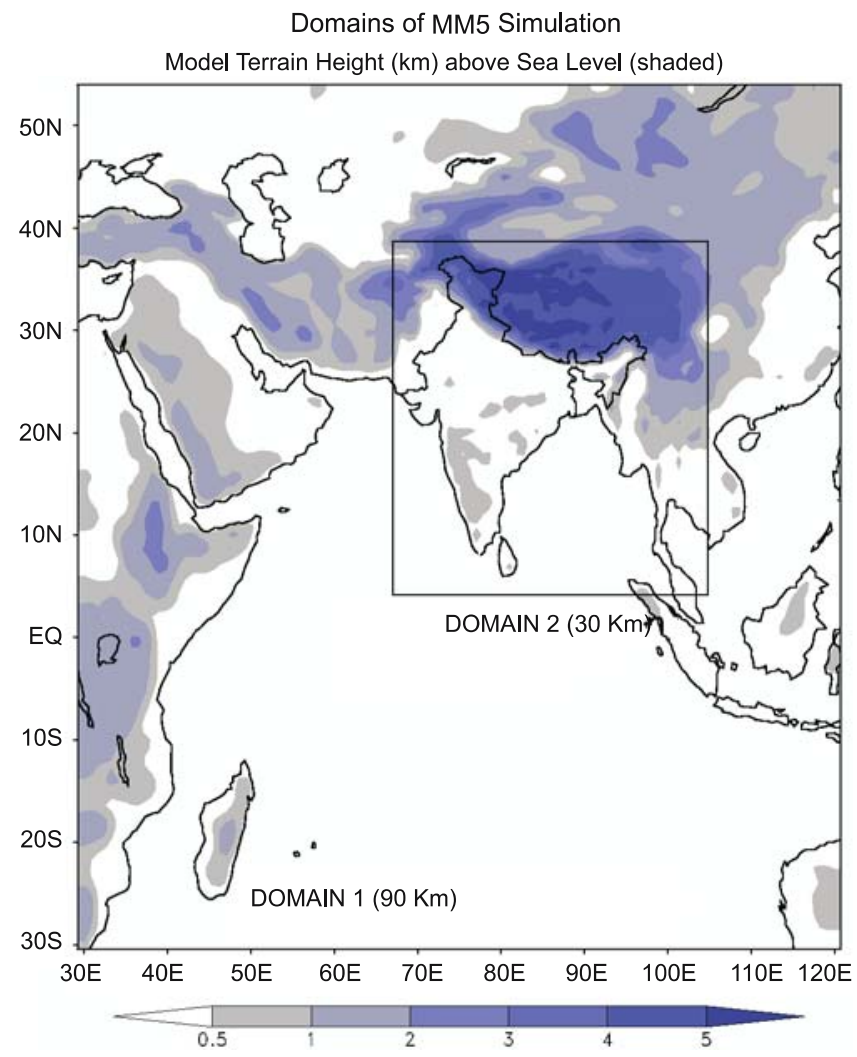

Figure 1. Domains of MM5 simulations. Shading indicates topography in $\mathrm{km}$.

In 2002, the seasonal rainfall was excess in one, normal in 14, deficient in 19 and scanty in two meteorological sub-divisions. Seasonal total rainfall for the country as a whole was below normal and country received $81 \%$ of its long period average rainfall.

\subsection{Domain of study}

MM5 model has been simulated over two nested domains of resolution $90 \mathrm{~km}$ and $30 \mathrm{~km}$, respectively (figure 1). We have discussed the results mainly for the inner domain-2 (30 km resolution).

For detailed rainfall study, seven small regions within the Indian domain $\left(4.2^{\circ}-38.7^{\circ} \mathrm{N}, 67.0^{\circ}-\right.$ $104.8^{\circ} \mathrm{E}$ ) have been considered (figure 2 ), which are important for rainfall prediction, and have wide variability of rainfall within it.
i. North India
$\left(28.5-32.5^{\circ} \mathrm{N}, 75.5-80.5^{\circ} \mathrm{E}\right)$
ii. Central India
$\left(16.5-26.5^{\circ} \mathrm{N}, 74.5-86.5^{\circ} \mathrm{E}\right)$
iii. East India
$\left(21.5-26.5^{\circ} \mathrm{N}, 84.5-88.5^{\circ} \mathrm{E}\right)$
iv. North-east
$\left(25.0-28.5^{\circ} \mathrm{N}, 91.5-96.5^{\circ} \mathrm{E}\right)$
India
v. Head Bay
$\left(18.0-21.0^{\circ} \mathrm{N}, 87.0-92.5^{\circ} \mathrm{E}\right)$
vi. Deccan coast

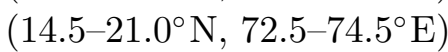
vii Konkan coast

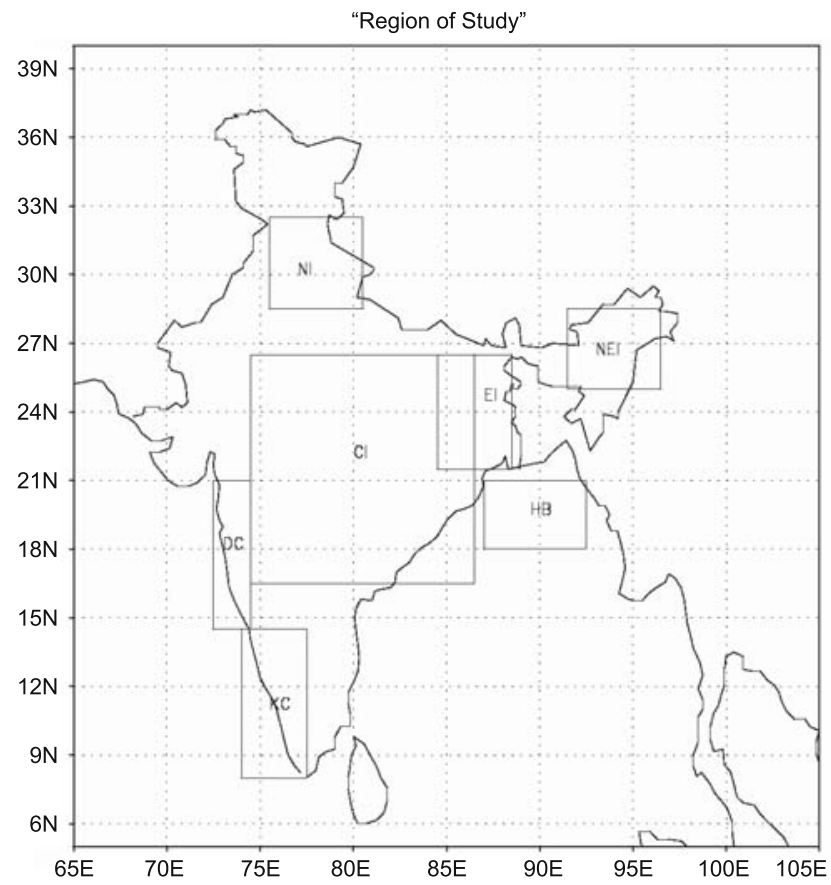

Figure 2. Domains for regional study - north India (NI), central India (CI), east India (EI), northeast India (NEI), Head Bay (HB), Deccan coast (DC) and Konkan coast (KC).

\subsection{Data used}

\subsubsection{Vegetation data}

MM5 simulations for the five years have been made independently, by using USGS (United States Geological Survey) and ISRO (Indian Space Research Organization) generated vegetation data. For the generation of vegetation by ISRO, the land use data derived for the reference year 2000 from multidate SPOT vegetation data (spatial resolution of about $1 \mathrm{~km}$ ) was re-aggregated/regrouped to USGS 25 classes, and spatially aggregated to $10^{\prime}$ grid size. Monthly vegetation fraction generated from temporally filtered 10-day NDVI composite of SPOT vegetation data over the Indian region were spatially aggregated to $10^{\prime}$ grid size (Shefali et al 2003; Oza et al 2006). Figure 3 represents the USGS and ISRO generated vegetation fraction over the Indian domain and their respective difference plot for the months of July and August for the year 1998. It is seen from the difference plot that the ISRO generated data is producing greater spatial coverage over the Indian region than the USGS data, except over the northeastern India and foothills of Himalayas where USGS vegetation fraction is greater.

Henceforth all simulation using the USGS vegetation are referred to as MM5-USGS and the simulation using the vegetation derived by ISRO (SAC) are referred to as MM5-ISRO. In this study an attempt has been made to highlight the effect of vegetation on model simulations. 

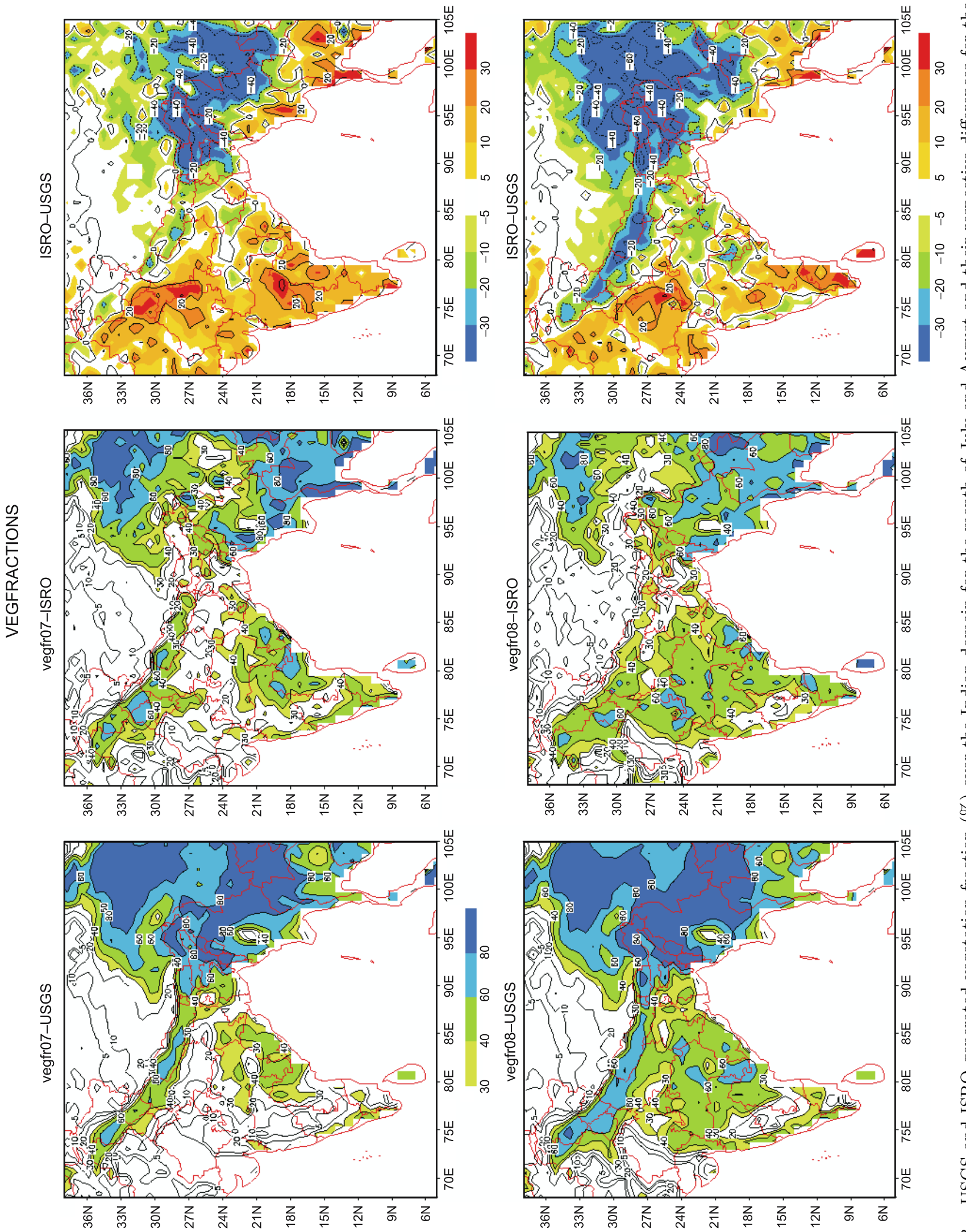

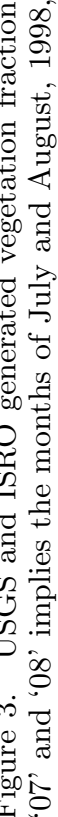




\subsubsection{Observed rainfall}

TRMM (Tropical Rainfall Measuring Mission) data has been used here as a ground truth for the verification of the rainfall simulations by the mesoscale model (http://daac.gsfc.nasa.gov/ precipitation/documentation.html). The TRMM satellite uses a passive sensor TRMM Microwave Imager (TMI), an active Precipitation Radar (PR) operating at $13.6 \mathrm{GHz}$, and a visible and infrared scanner (VIRS) radiometer. The 3B42 algorithm provides daily precipitation and root mean square (RMS) error estimates at $0.25^{\circ} \times 0.25^{\circ}$ latitude/longitude grids over $50^{\circ} \mathrm{N}$ to $50^{\circ} \mathrm{S}$ for Version-6 (V6). Rain gauge analysis from GPCP is also merged with the sensor data. Here, we have used the 3B42-V6 data, which is available in a spatial resolution of $0.25^{\circ} \times 0.25^{\circ}$ latitude/longitude grids and over 3 hourly temporal scales. Figure 4 represents the July and JJAS mean rainfall for the years 1998 and 2002 over the Indian domain as captured by TRMM. A detailed comparison of observed rainfall between three sources namely TRMM, GPCP and IMD for the years 1998 and 2002 is given in Das et al (2007). The purpose of the said comparison between the observational datasets of rainfall was to find the most suitable datasets among TRMM, GPCP and IMD for comparison with the model-simulated rainfall. Since, IMD data is confined only within the Indian landmass; validation of the model outputs over the seas was not possible with it. Between TRMM and GPCP, in most of the cases standard deviation of TRMM was higher than that of GPCP. But, it was able to produce rainfall amount closer to that of IMD, both over the smaller regions and for whole India. Over sea, the higher rainfall signatures were present in both TRMM and GPCP. TRMM being of higher resolution $\left(0.25^{\circ} \times 0.25^{\circ}\right)$ had succeeded in capturing the rainfall distribution in finer details throughout the Indian Domain. Therefore, the TRMM dataset was selected for validation of model results.

Daily mean data of NCEP-Reanalysis II has been used here for verification of the wind fields and surface parameters simulated by the model (Kanamitsu et al 2002) (http://www.cpc.ncep. noaa.gov/products/wesley/reanalysis2/kana/rean12-1.htm). They serve as a proxy to observations for the validation of model outputs, in particular, the winds and surface parameters.

\section{Results and discussions}

In this section the model simulated outputs using both USGS and ISRO generated vegetation data are compared with that of ground truth. Beginning with discussions on rainfall simulations for normal and deficient monsoon years, elaborate discussions of simulated wind fields at 850 and $200 \mathrm{hPa}$ have been done. The $2 \mathrm{~m}$ air temperature simulated by the model is considered as one of the important surface parameters sensitive to vegetation fraction.

\subsection{Rainfall}

For brevity, elaborate results are discussed here only for the month of July and JJAS of 1998 and 2002. For the remaining years (1999-2001), results are discussed only for JJAS. Detailed results of all months are presented in Das et al (2007). Figures 5 and 7 , and 6 and 8 depict the mean July and JJAS rainfall, respectively, as simulated by MM5 using USGS and ISRO vegetation, for the years 1998 and 2002 , respectively. In the month of July, in both the years MM5-USGS is better over north and central India. In 1998, MM5-USGS has performed better over the foothills of the Himalayas but has overestimated rainfall over the Head Bay, more compared to MM5-ISRO. From the difference plots it is clear that the rainfall over the western coast is in close proximity to TRMM for both USGS and ISRO. MM5-ISRO is better in July 1998 over the region. Over the Arabian Sea, model has overestimated rainfall in both the years.

From the mean JJAS rainfall, for both 1998 (figure 6) and 2002 (figure 8), it is clear that MM5-ISRO has performed relatively better over northeast India. In 1998, MM5-ISRO has simulated better over western coast and MM5-USGS over north India. In both the years, model has overestimated rainfall over the Arabian Sea and Bay of Bengal. Figures 9-11, present the mean JJAS rainfall for the years 1999-2001. From the difference plots we find that in 1999, MM5-ISRO is better over central India with rainfall amounts similar to TRMM. Over other parts, USGS and ISRO have similar results. In 2000, MM5-ISRO has little improvement over north India whereas, MM5-USGS results are better over north-eastern region. Situation reverses for 2001. Over the western coast, MM5-ISRO simulated rainfall is closer to TRMM for all the three years 1999-2001.

Figures 12 and 13 depict the histograms of area averaged total rainfall for the two contrasting monsoon seasons of 1998 and 2002 for different sectors over the Indian region. From the histograms it is seen that out of the 16 cases of JJAS rainfall, the MM5-ISRO and MM5-USGS are showing similar results, each being better in eight cases. MM5-ISRO has simulated JJAS rainfall better over central India, northeast India, Head Bay, and Konkan coast and over All-India in the normal monsoon year. MM5-USGS, on the other hand has produced better JJAS rainfall over north 
TRMM Mean Rainfall(cm/day)
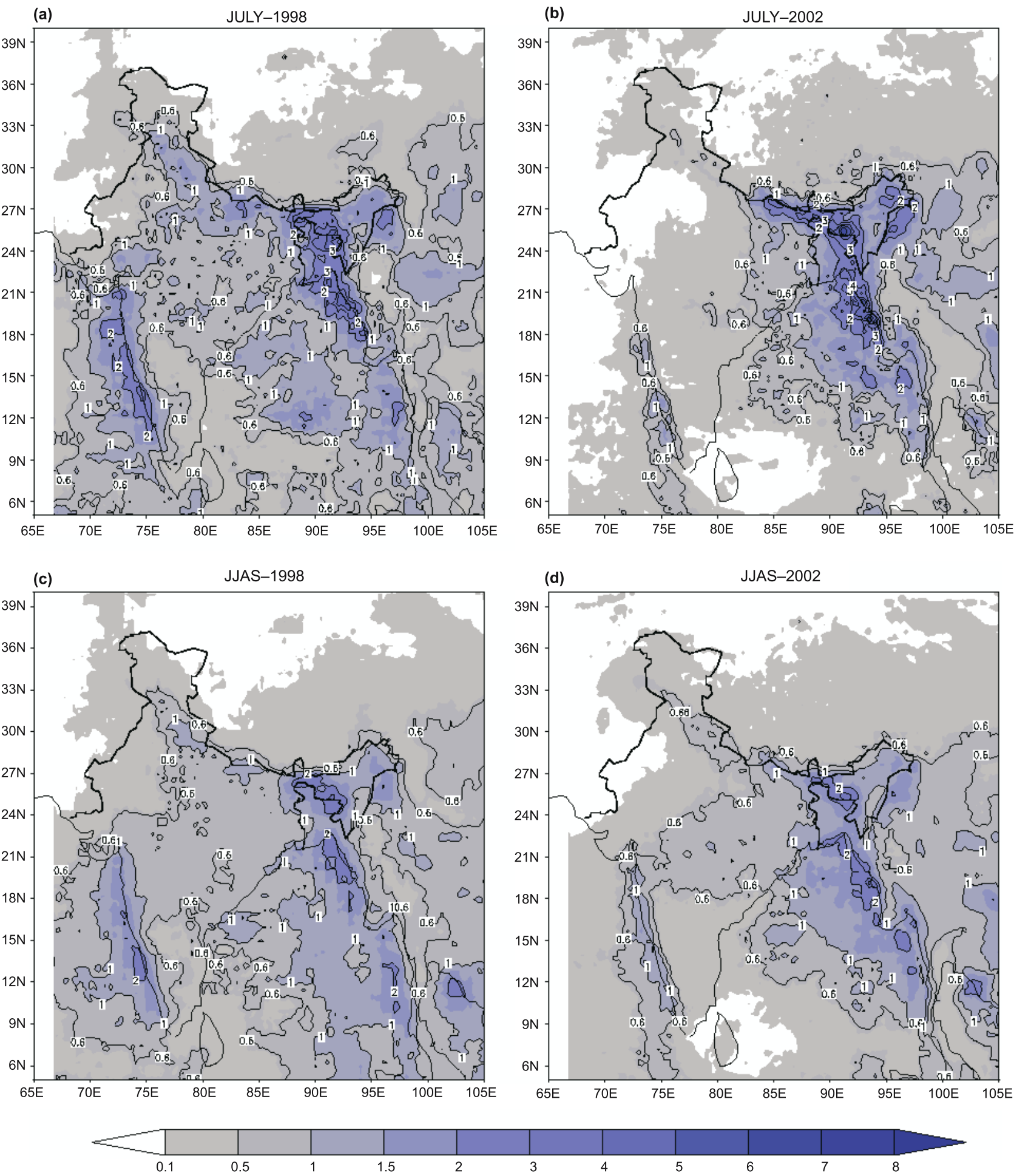

Figure 4. Mean rainfall (cm/day) as captured by TRMM for (a) July 1998, (b) July 2002, (c) JJAS 1998, and (d) JJAS 2002.

India, central India, Head Bay, Deccan coast and Konkan coast in the deficient monsoon year. In total, MM5-ISRO is better in the normal monsoon and MM5-USGS in the deficient monsoon year. Over north India and Deccan coast, MM5-USGS has simulated JJAS total rainfall closer to TRMM in both 1998 and 2002, whereas MM5-ISRO has persistently simulated better JJAS rainfall over northeast India and for All-India.

From All India daily time series plot (figure 14), it is viewed that in 1998 ISRO has simulated daily rainfall values closer to TRMM. In the same, USGS 
(a)

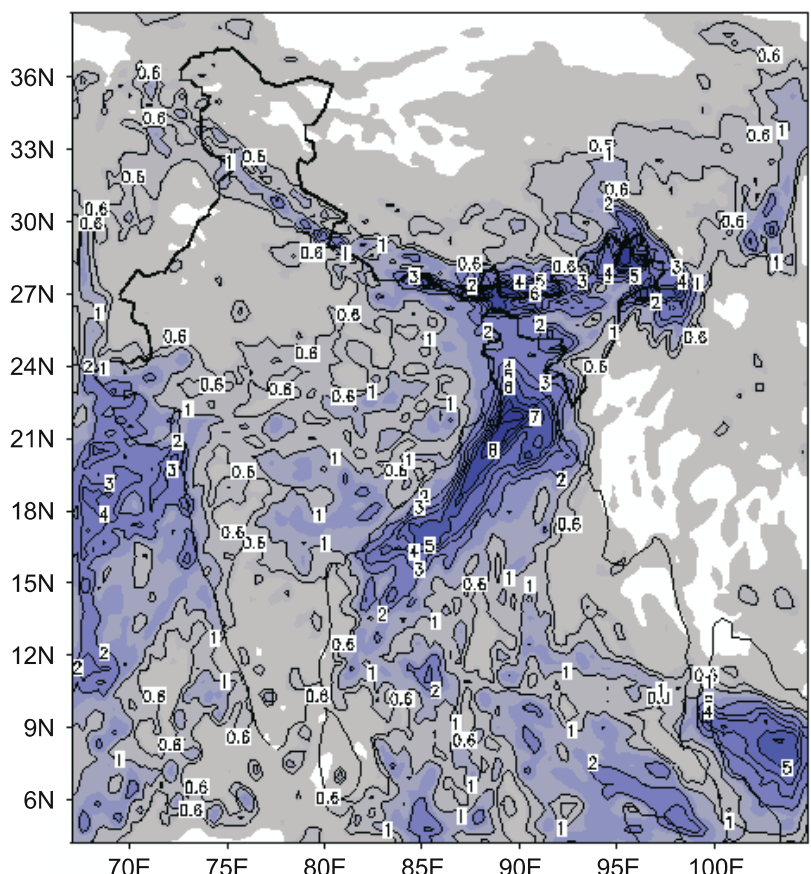

(b)

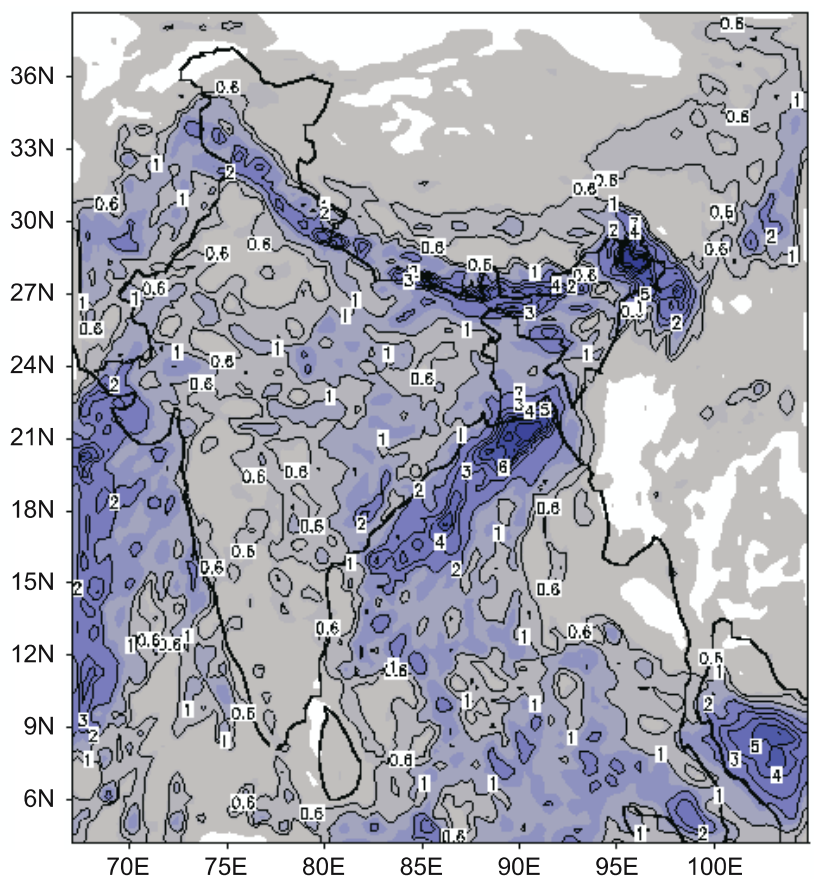

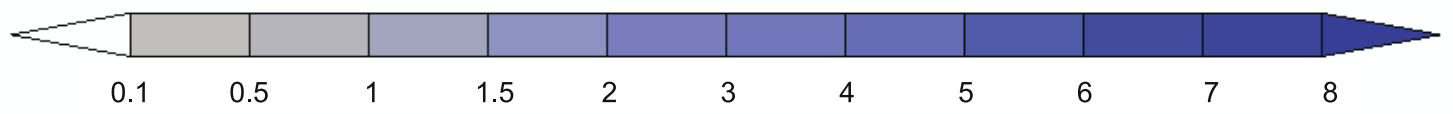

Difference of Mean July Rainfall (cm) - 1998

(c)

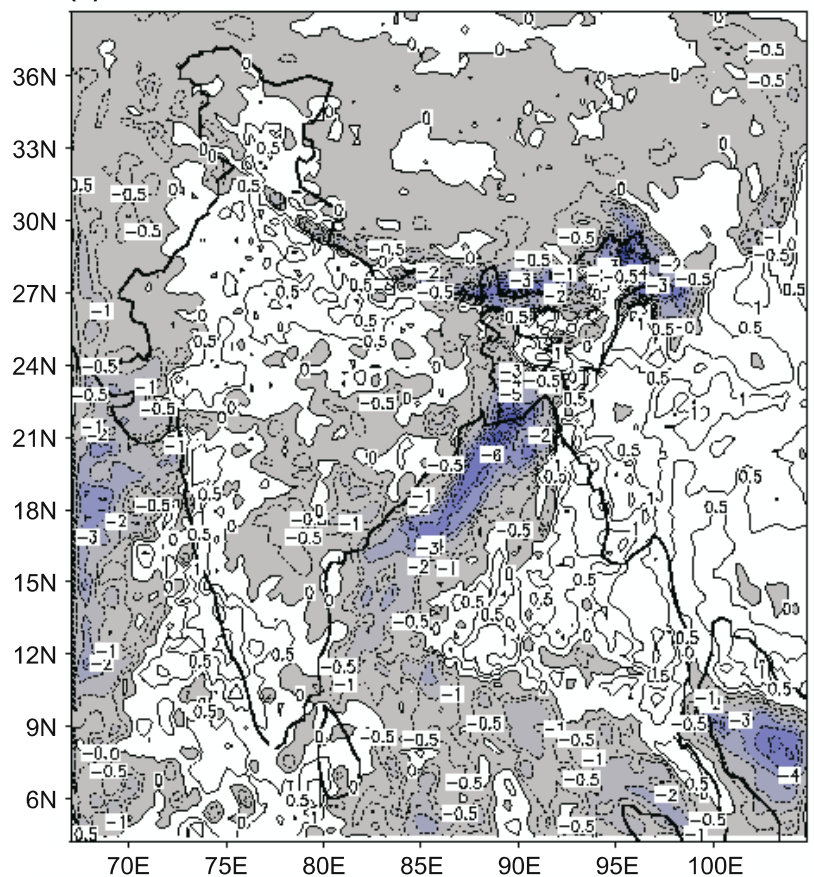

(d)

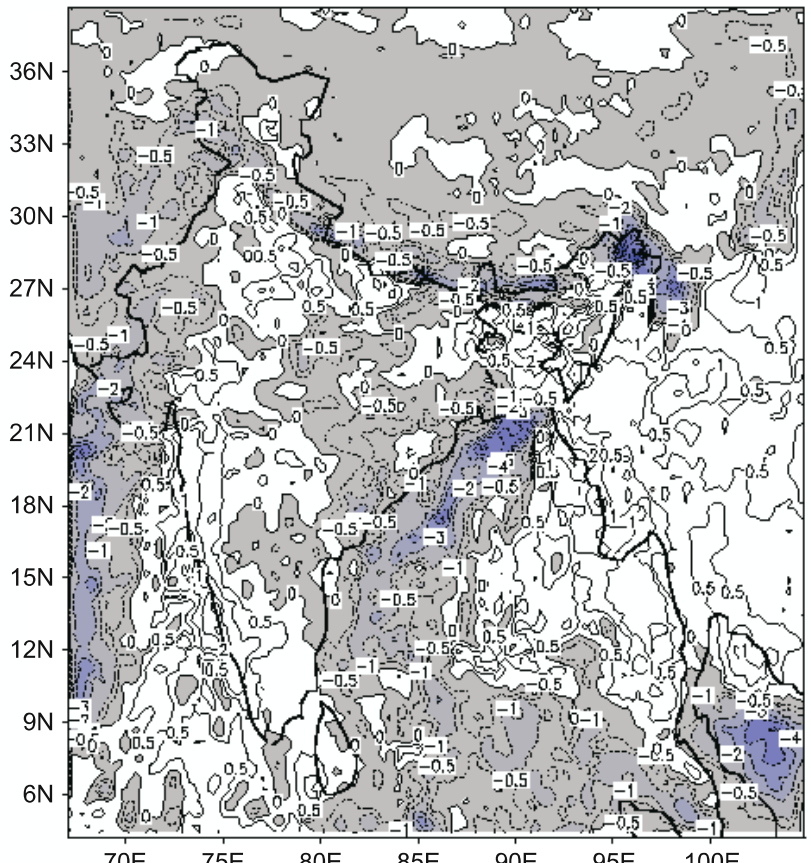

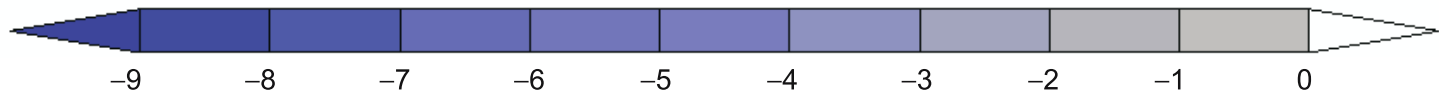

Figure 5. MM5 simulated mean rainfall (cm/day) for the month of July 1998 for (a) USGS and (b) ISRO. Difference $(\mathrm{cm})$ of MM5 simulated rainfall from TRMM rainfall for (c) USGS and (d) ISRO. The negative regions are shaded. 
Mean JJAS Rainfall (cm/day) - 1998

(a)

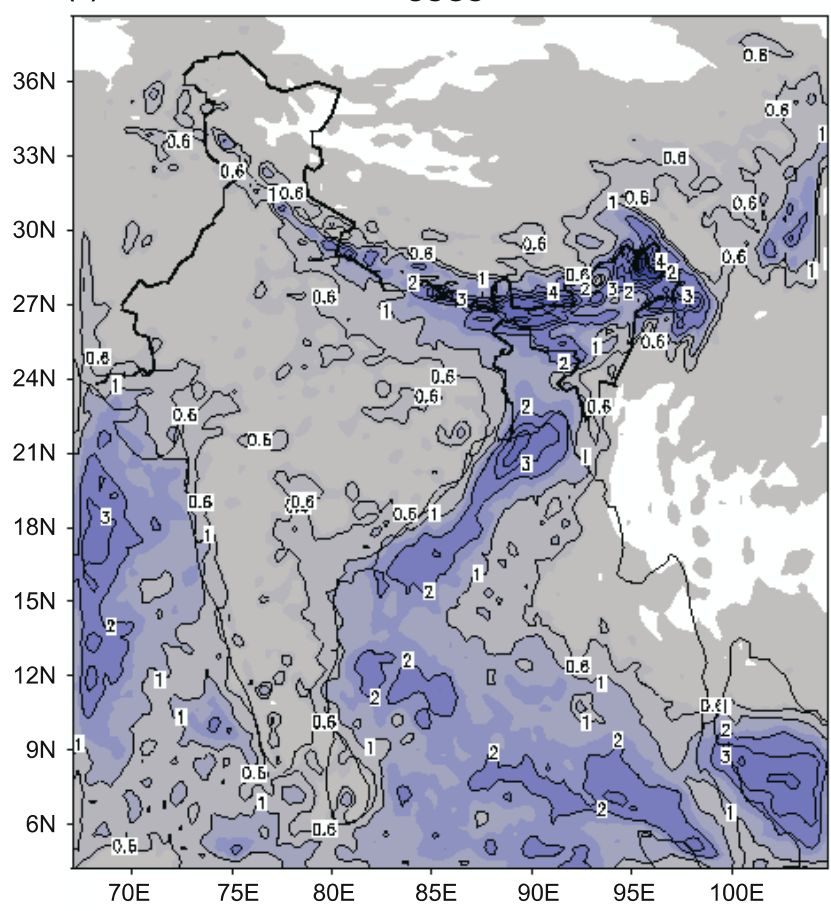

(b)

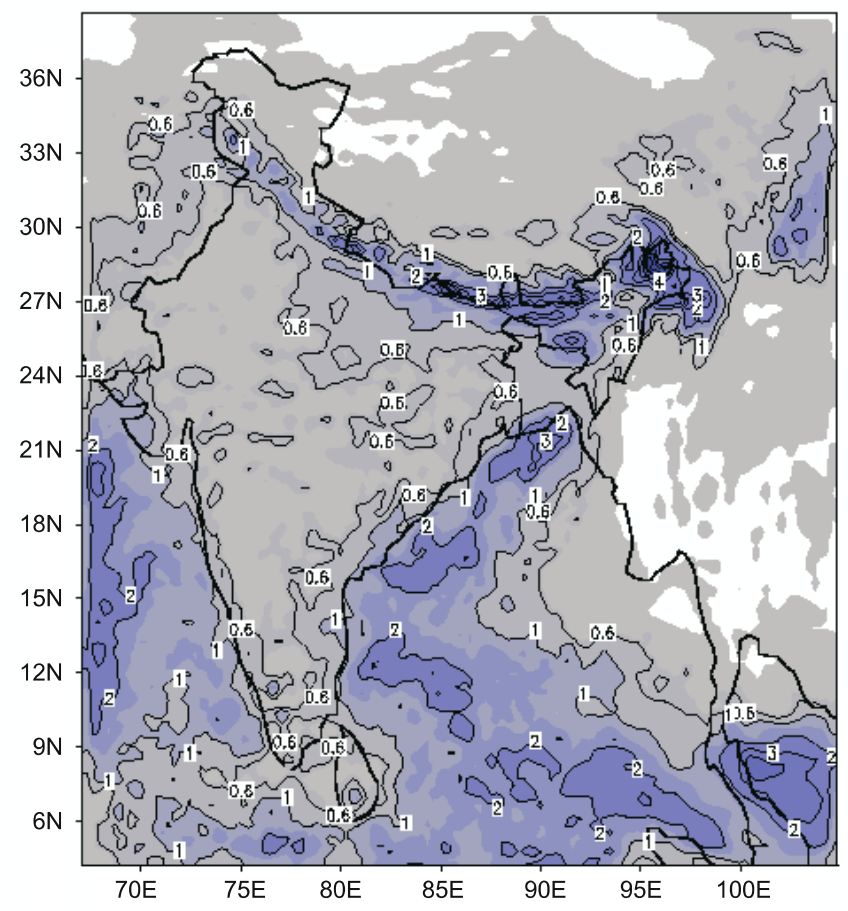

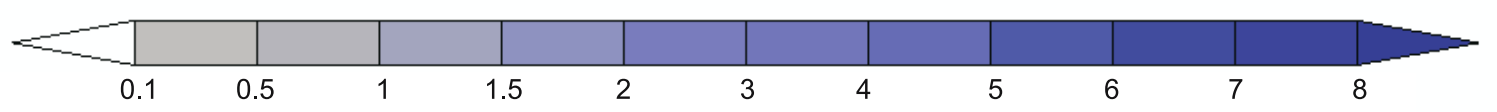

Difference of Mean JJAS Rainfall $(\mathrm{cm})-1998$

(c)

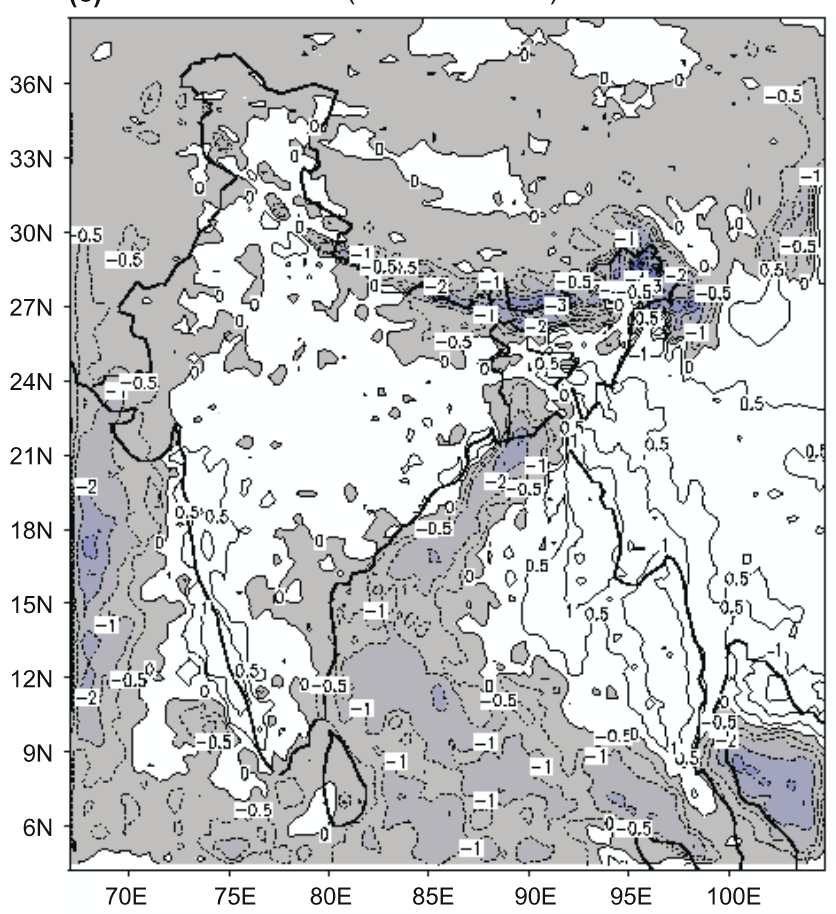

(d)

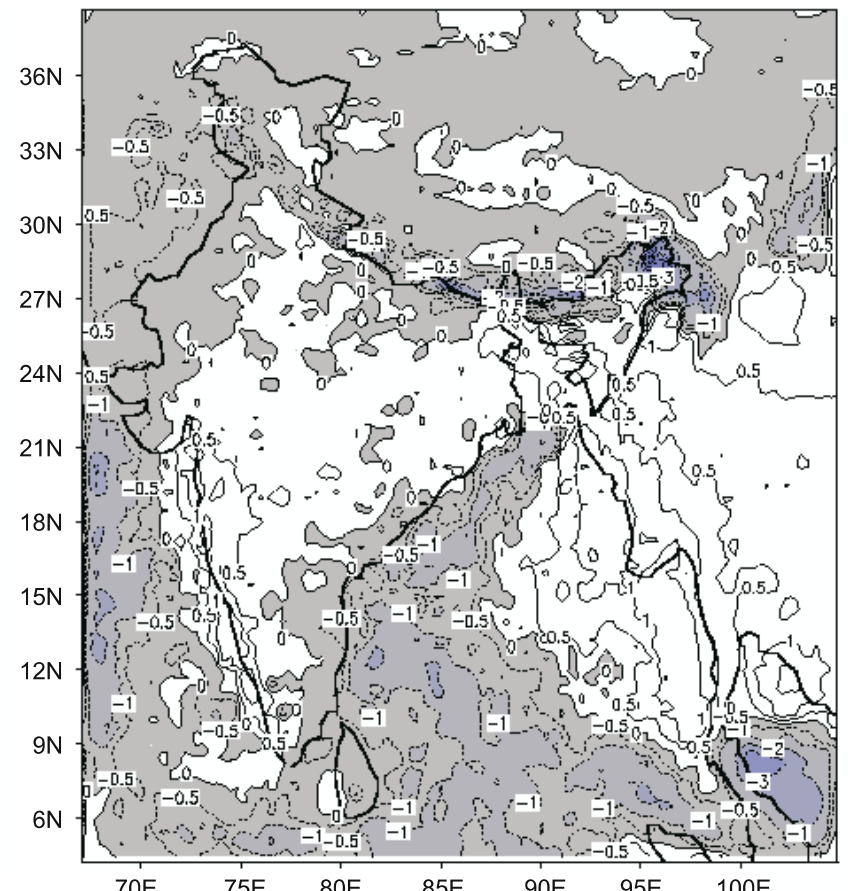

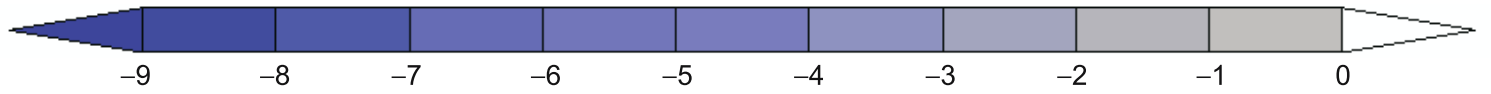

Figure 6. As in figure 5 but for JJAS 1998. 
(a)

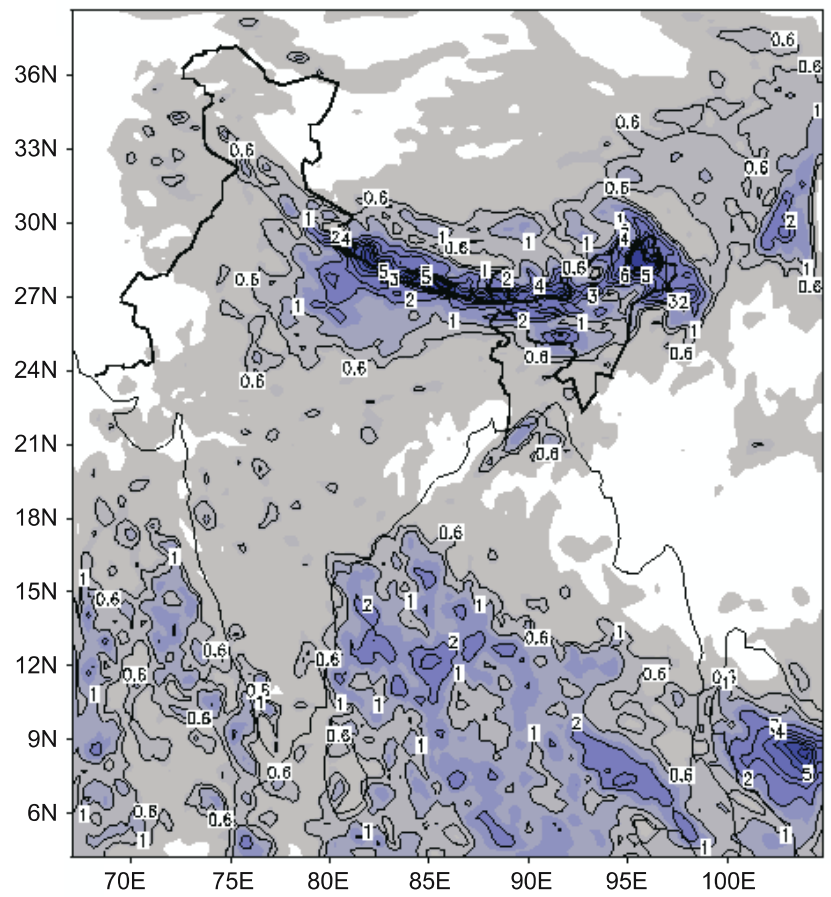

(b)

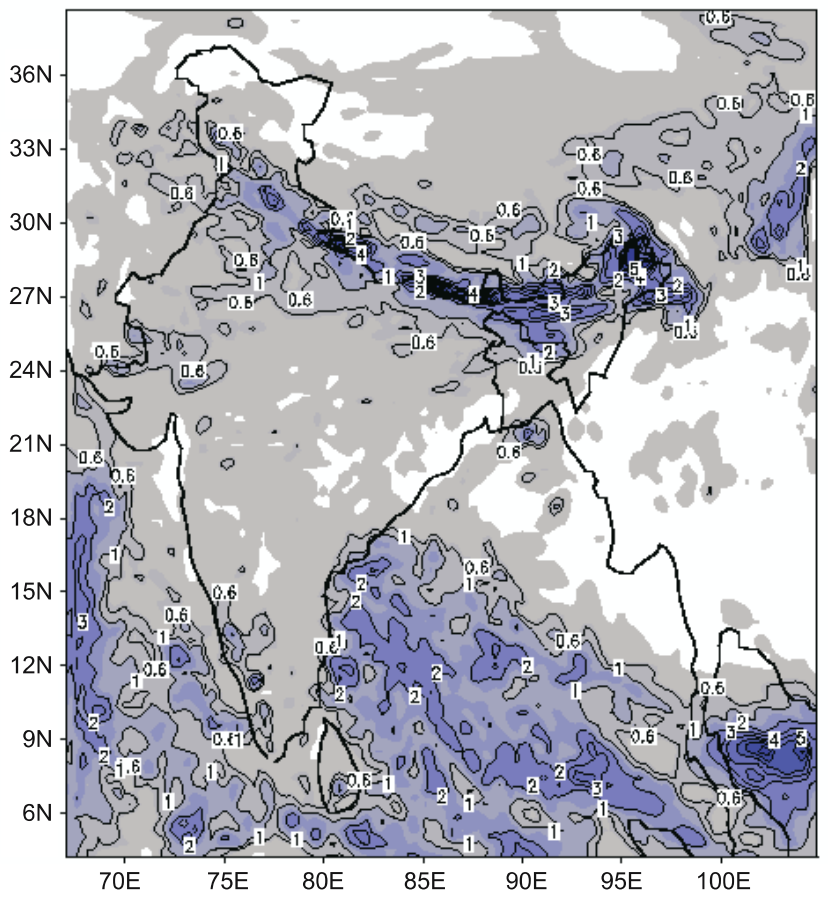

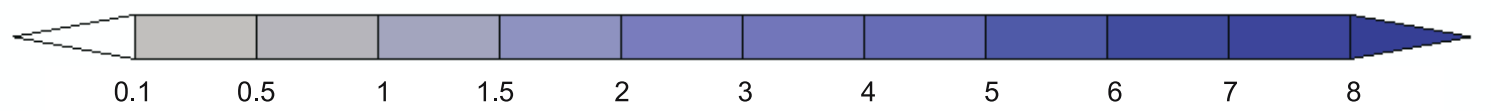

Difference of Mean July Rainfall (cm) - 2002

(c)

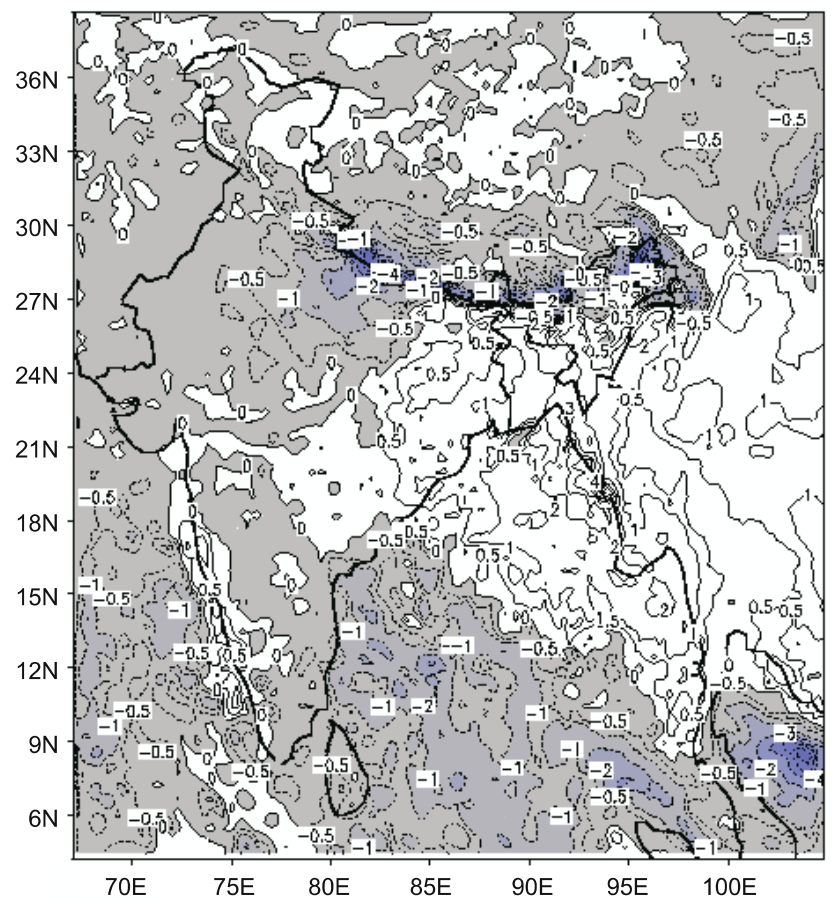

(d)

(TRMM - ISRO)

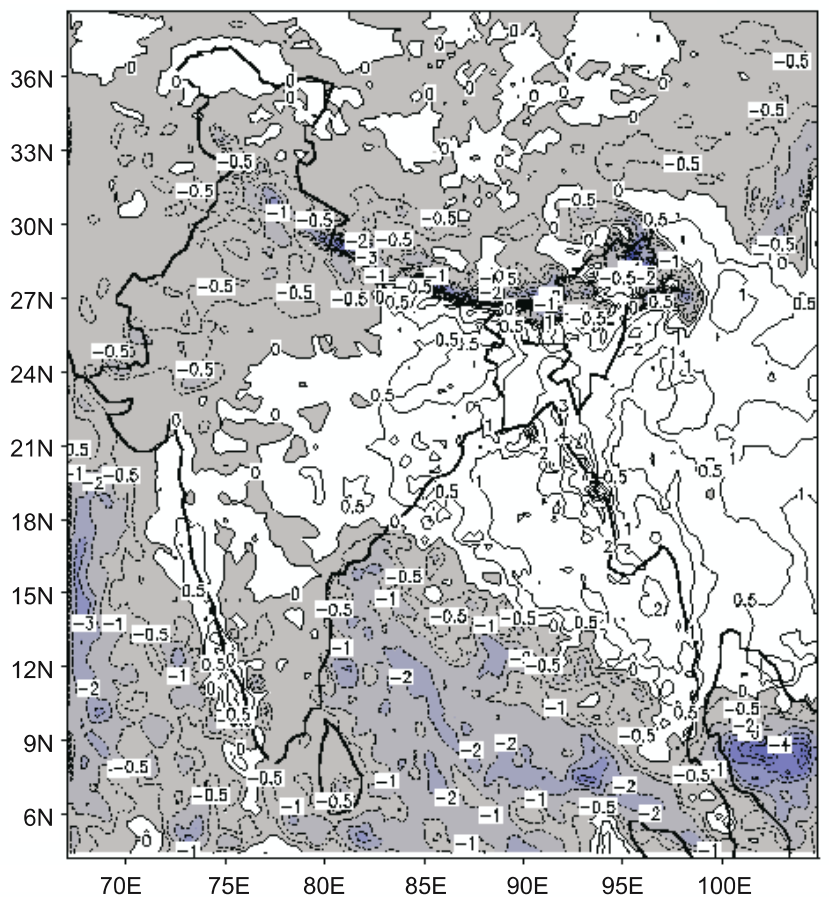

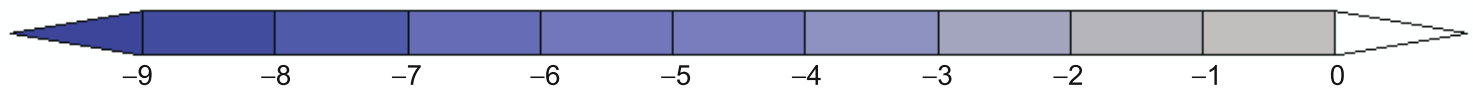

Figure 7. As in figure 5 but for July 2002. 
(a)

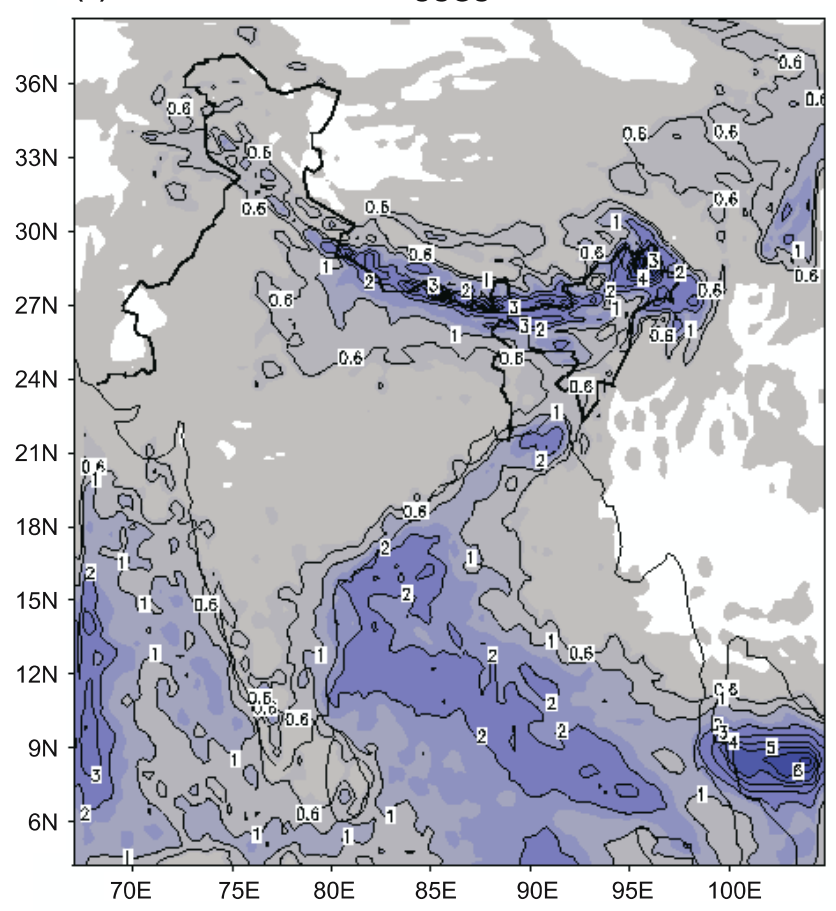

(b)

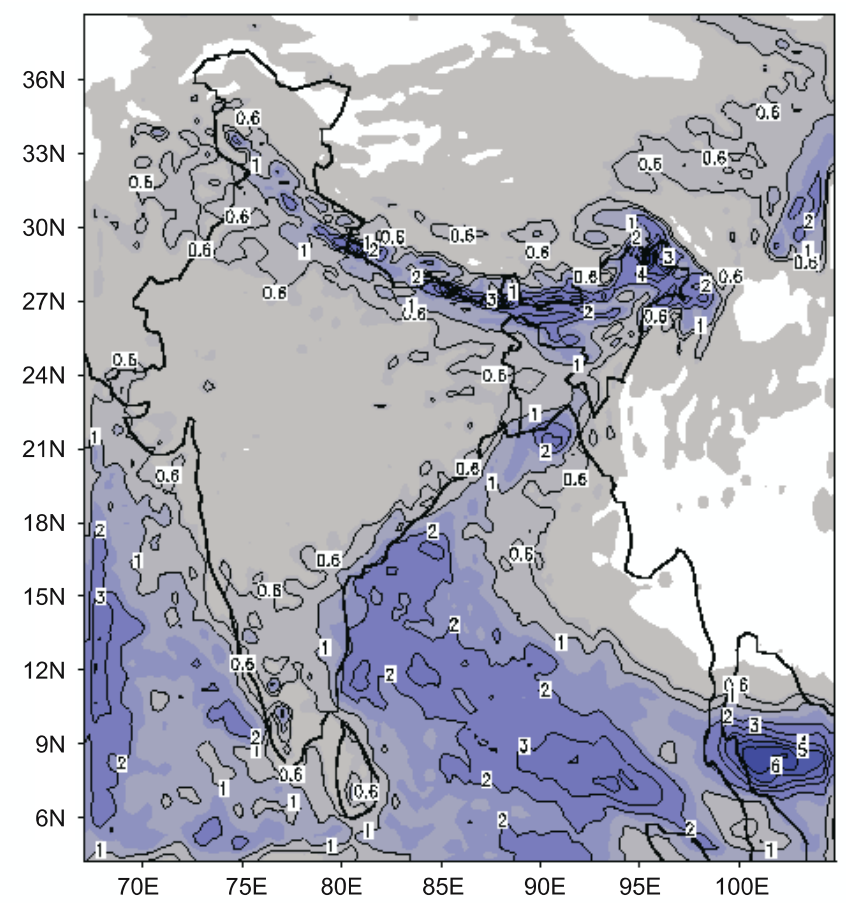

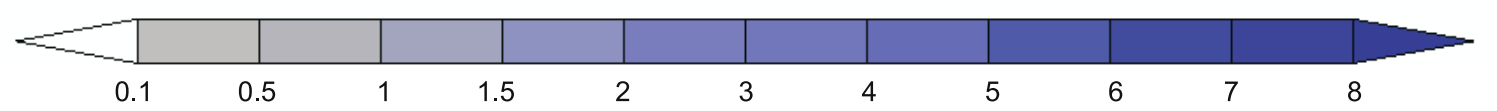

Difference of Mean JJAS Rainfall (cm) - 2002

(c)

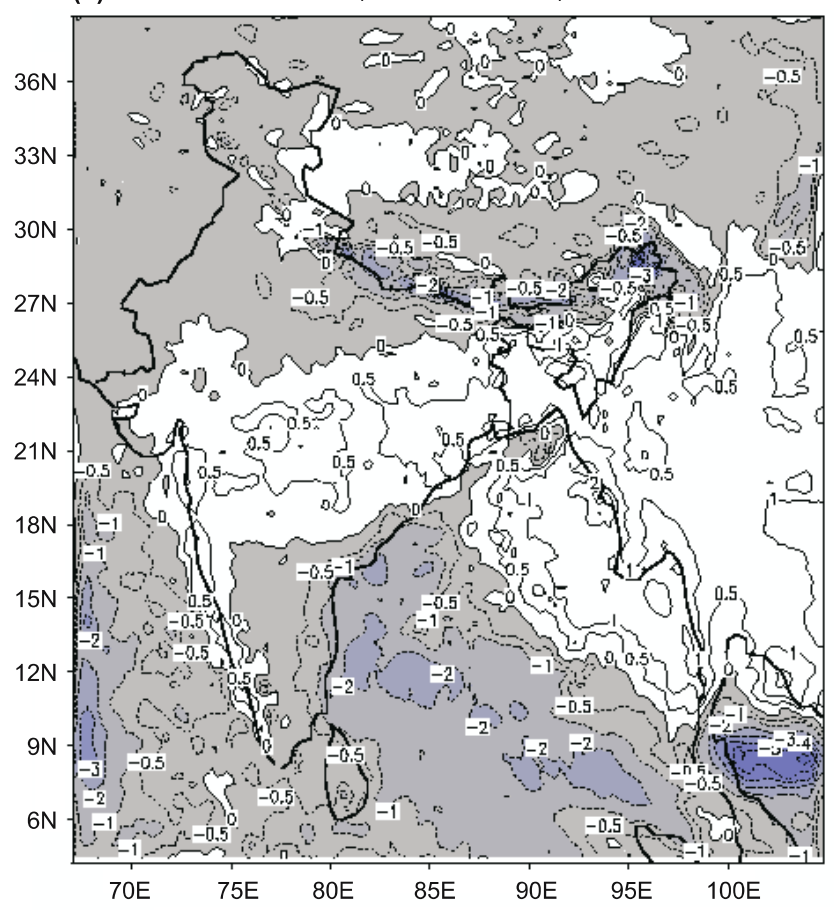

(d)

(TRMM - ISRO)

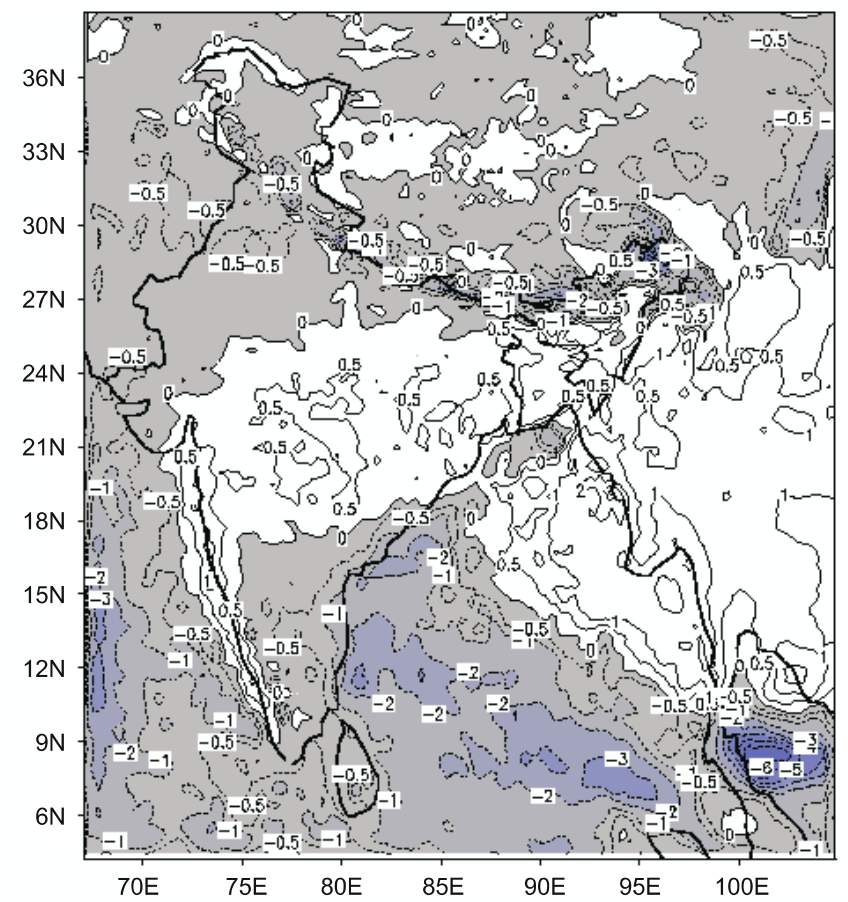

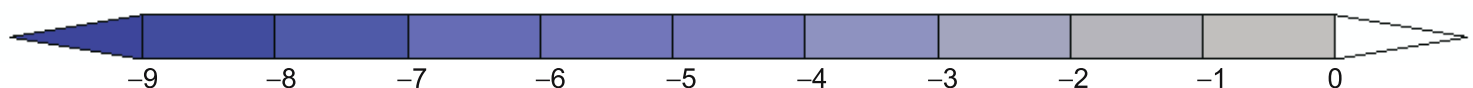

Figure 8. As in figure 5 but for JJAS 2002. 
Forecast — Mean JJAS Rainfall (cm/day) - 1999

(a)

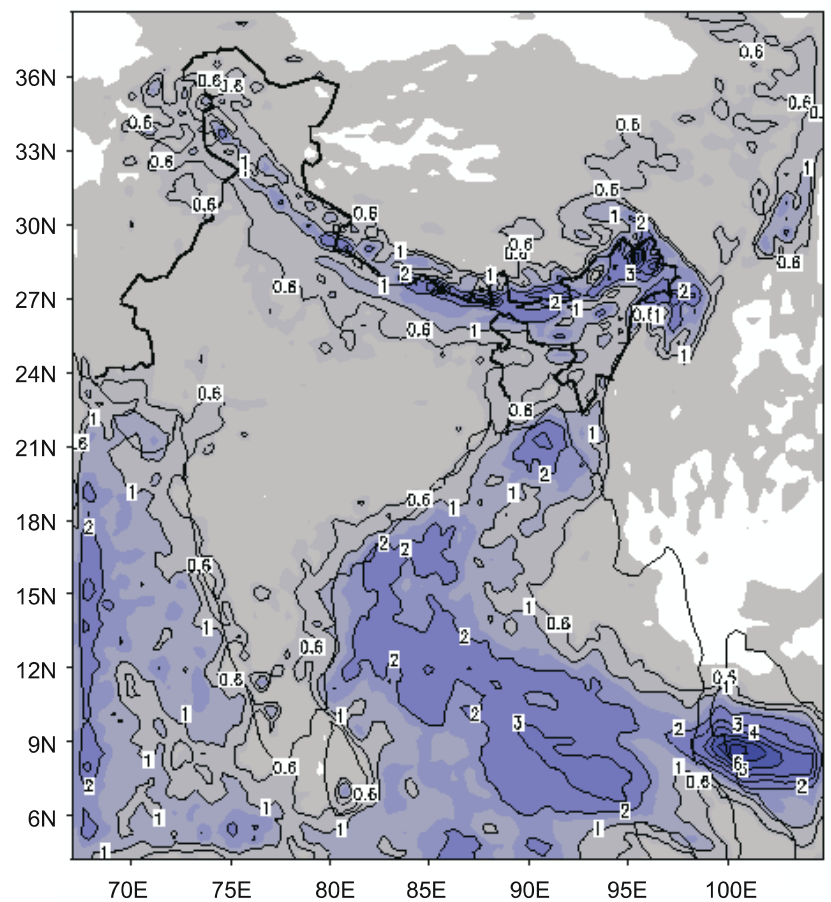

(b)

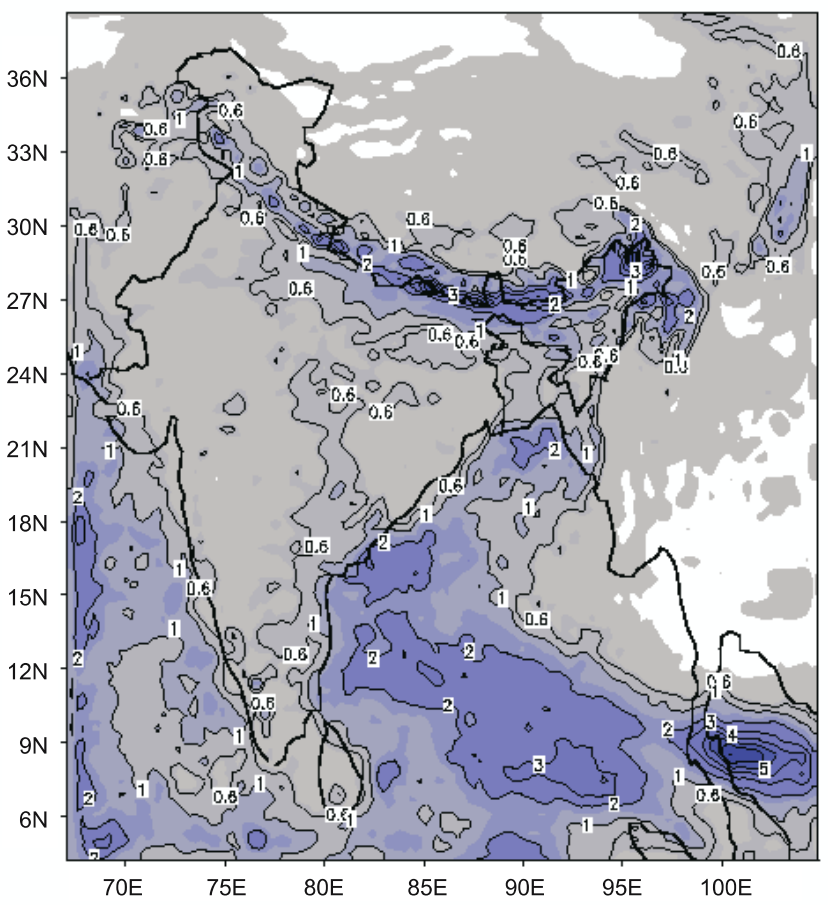

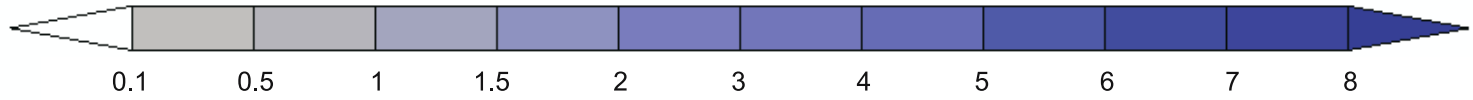

Difference of Mean JJAS Rainfall (cm) - 1999

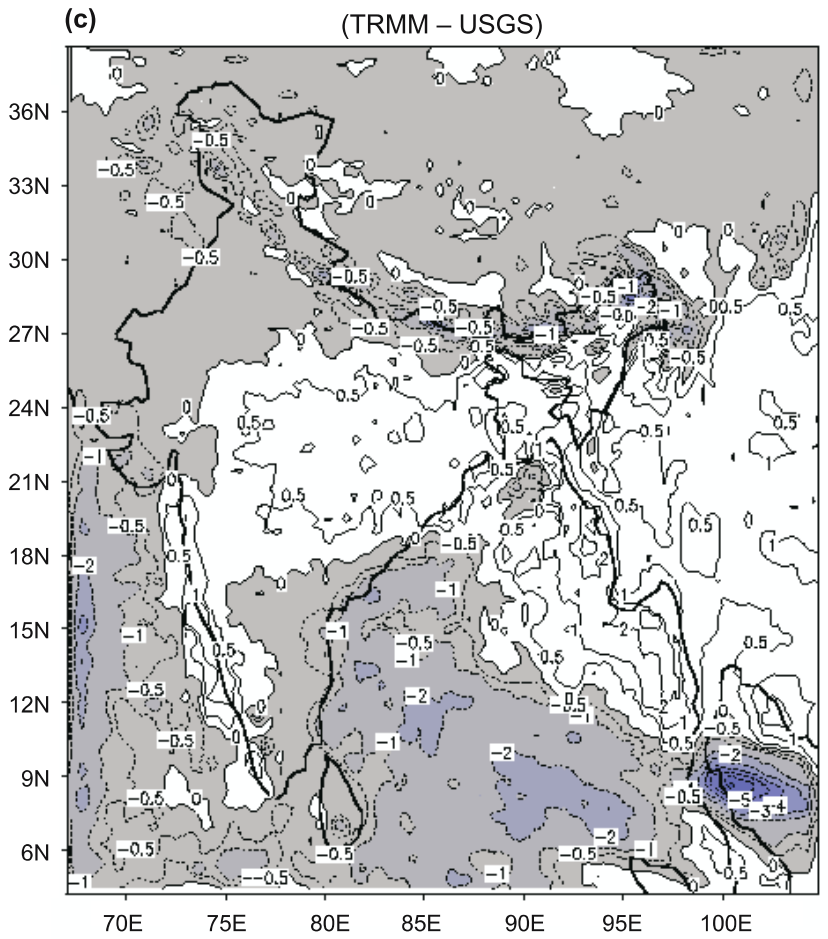

(d)

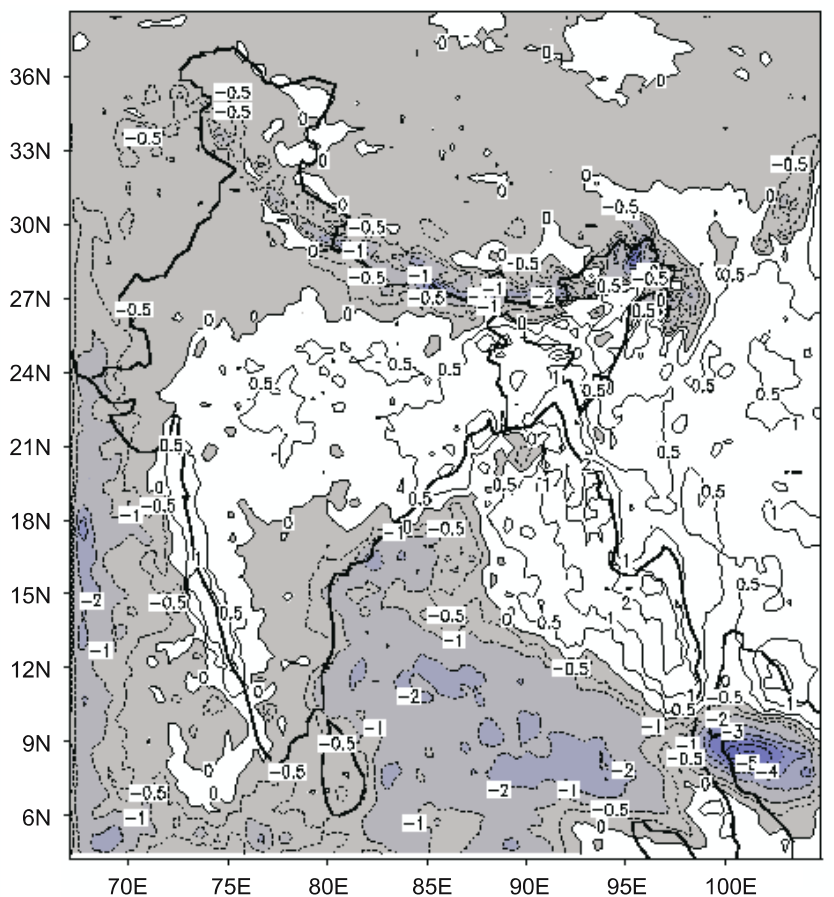

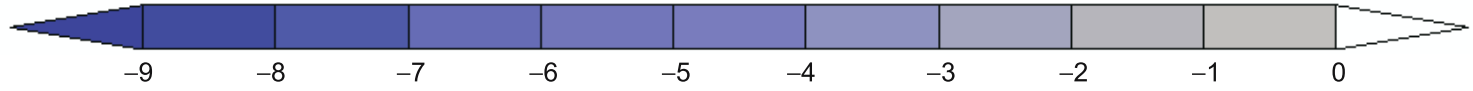

Figure 9. As in figure 5 but for JJAS 1999. 
(a)

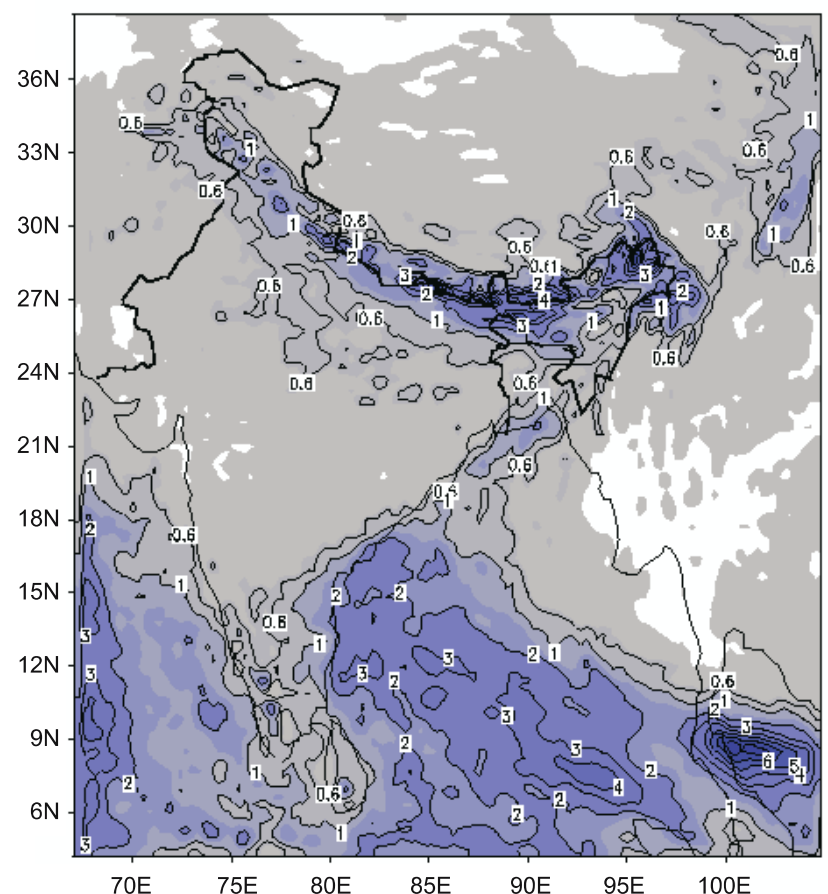

(b)

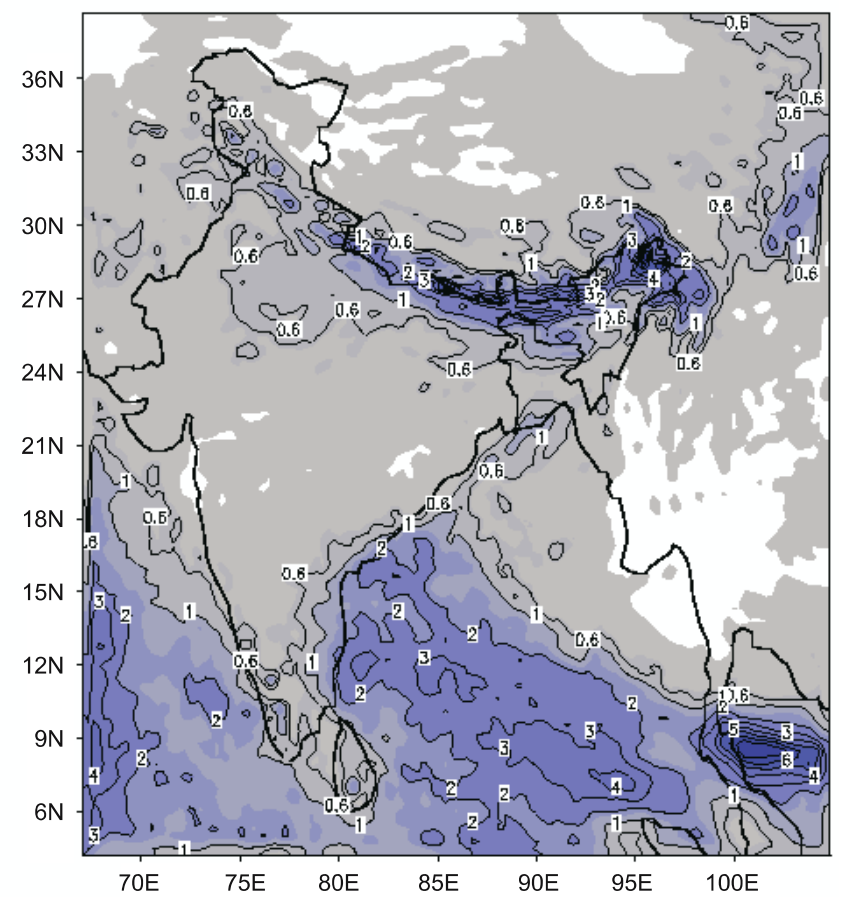

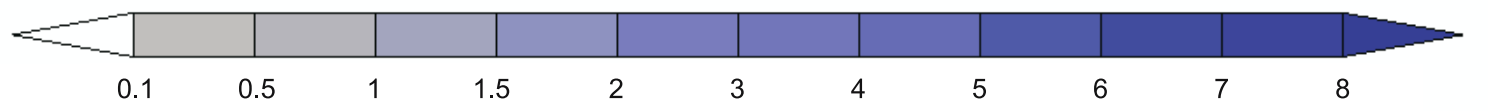

Difference of Mean JJAS Rainfall (cm) - 2000

(c)

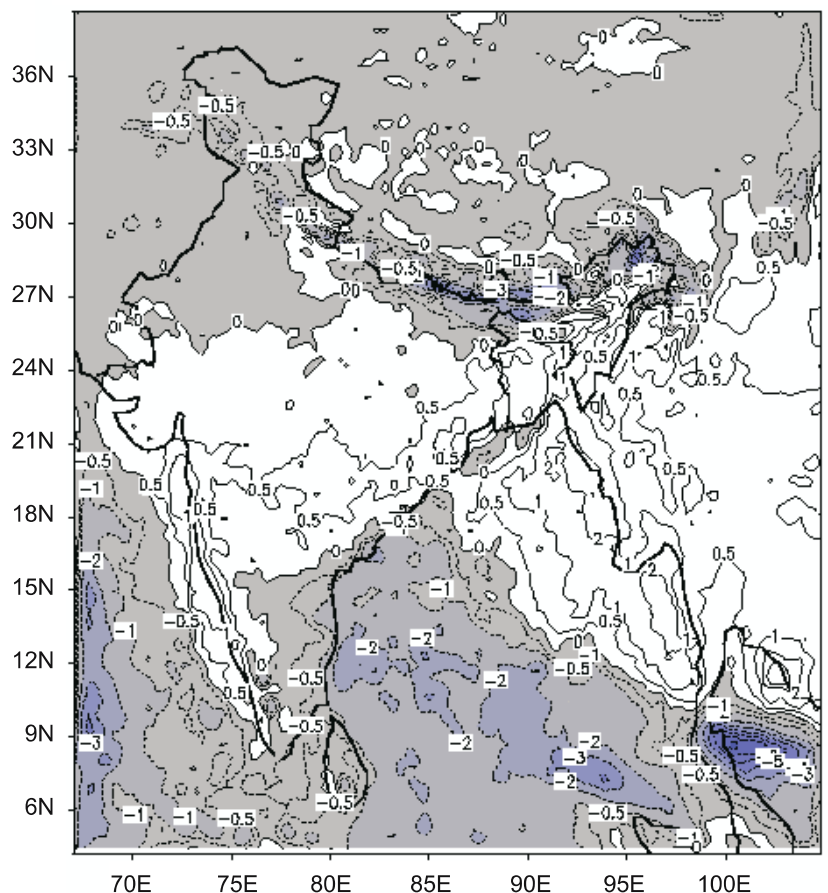

(d)

(TRMM - ISRO)

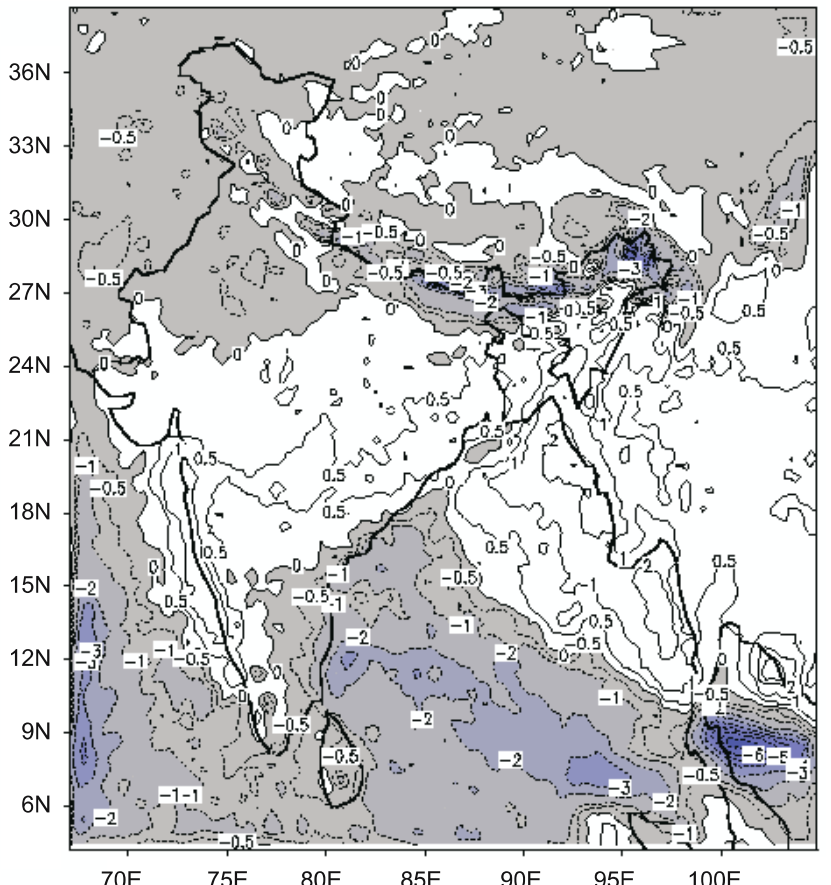

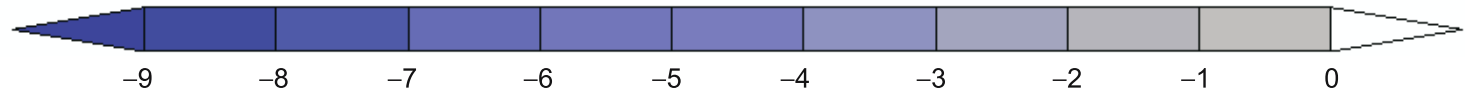

Figure 10. As in figure 5 but for JJAS 2000. 
(a)

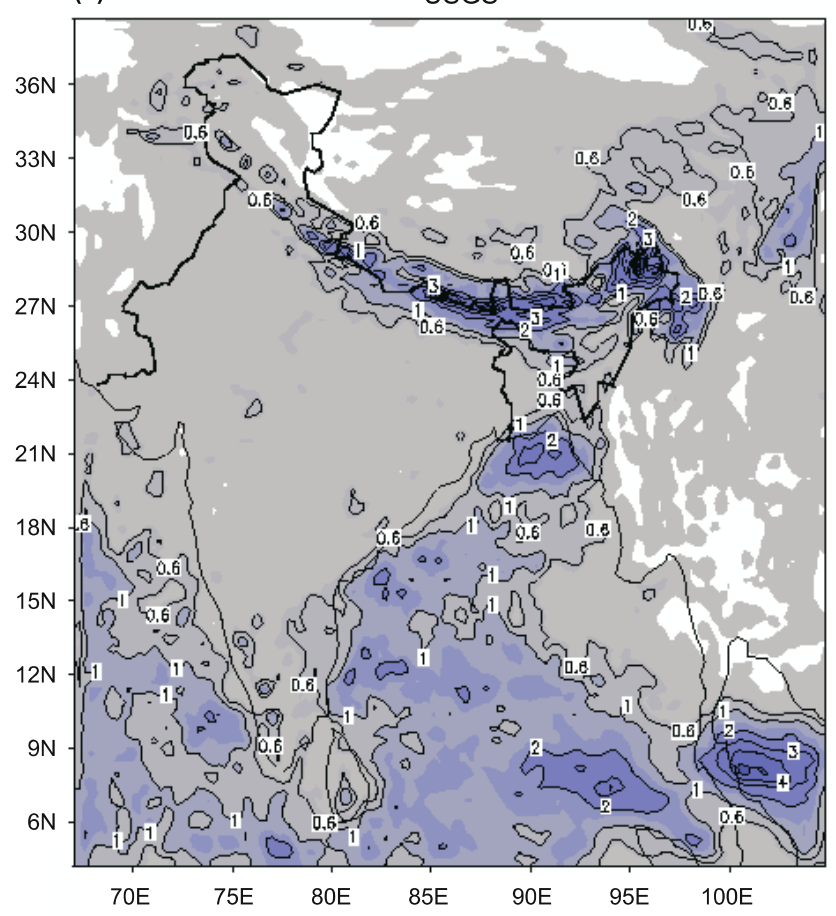

(b)

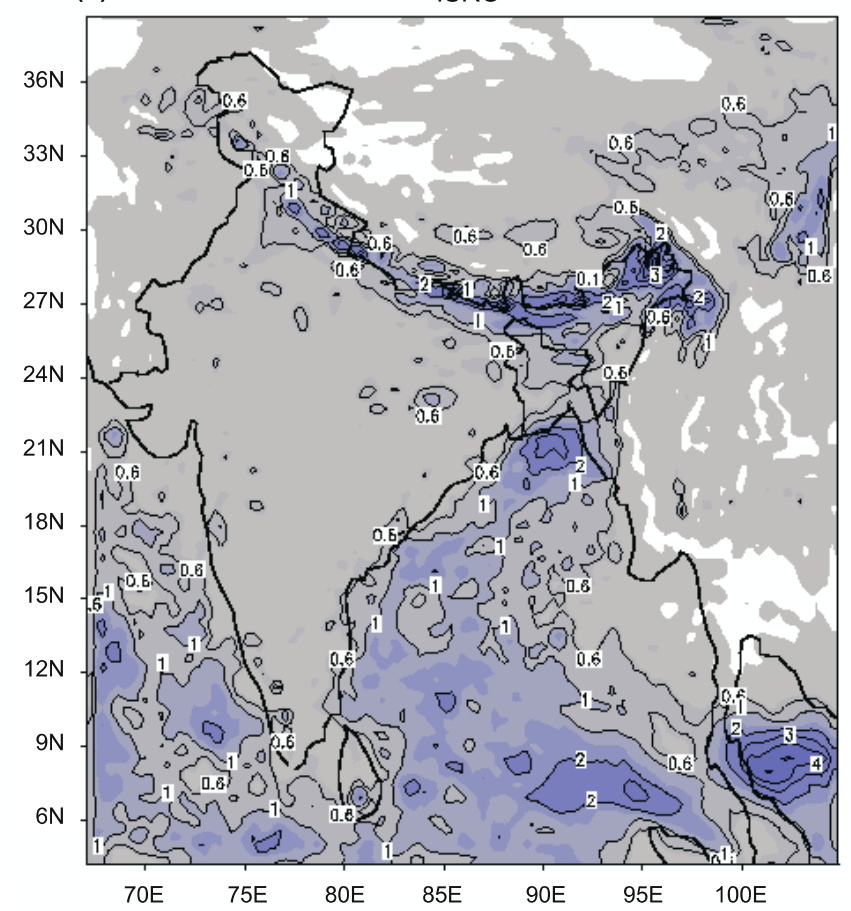

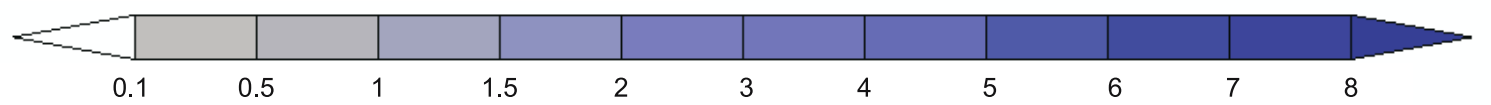

Difference of Mean JJAS Rainfall (cm) - 2001

(c)

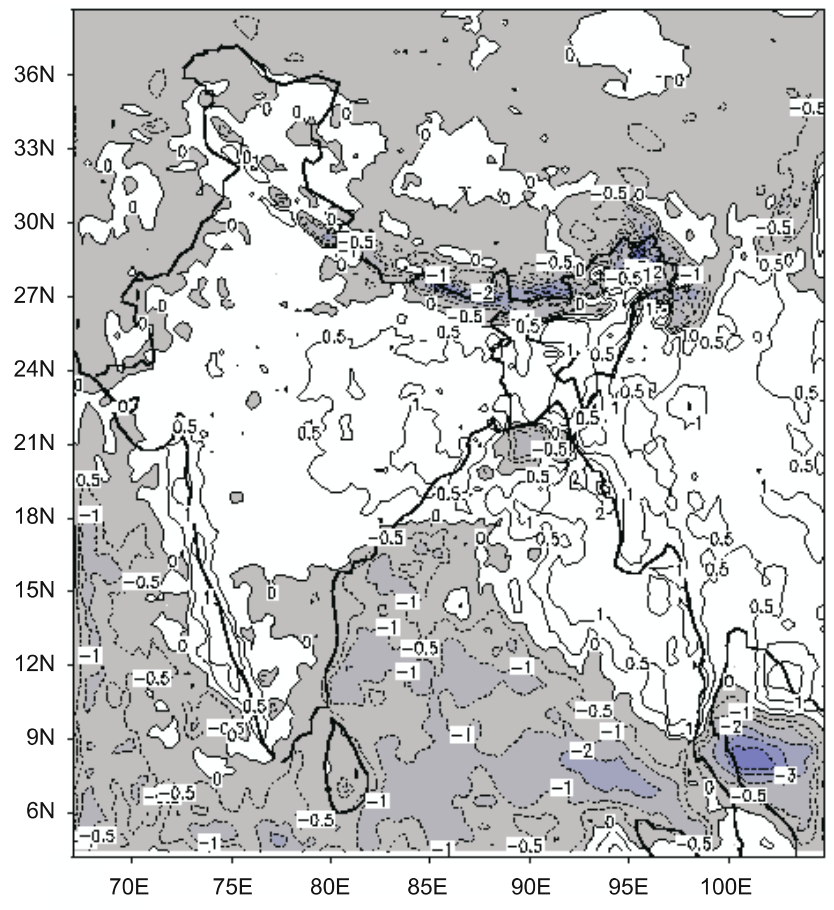

(d)

(TRMM - ISRO)

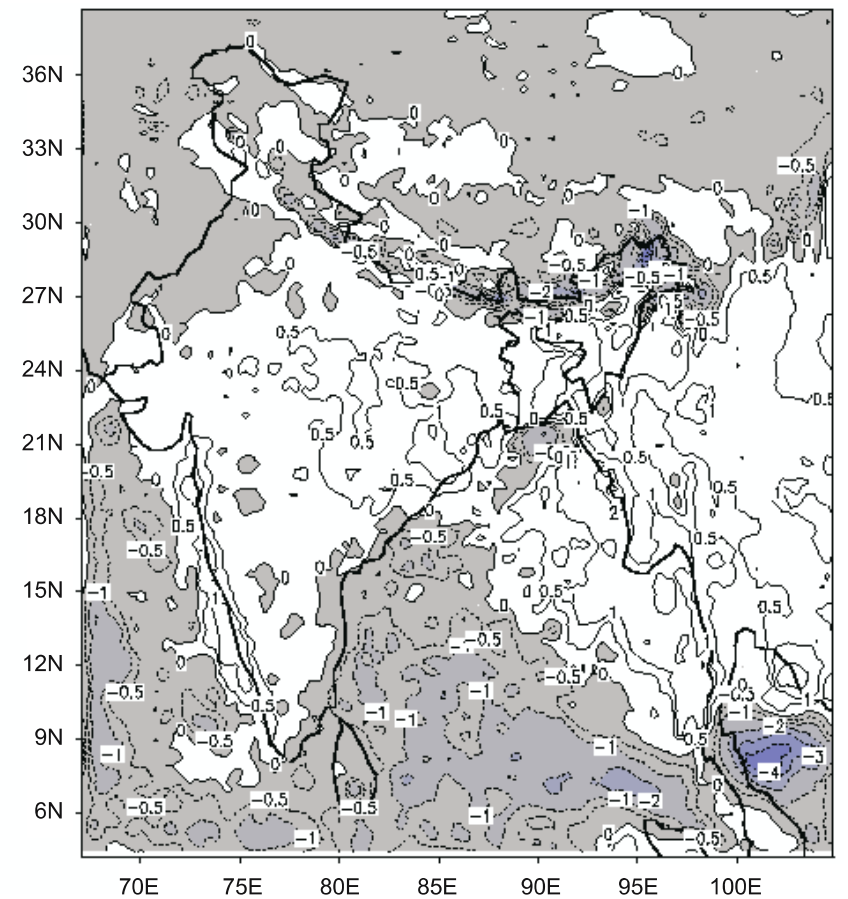

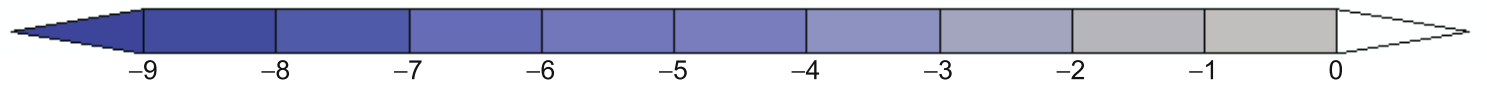

Figure 11. As in figure 5 but for JJAS 2001. 

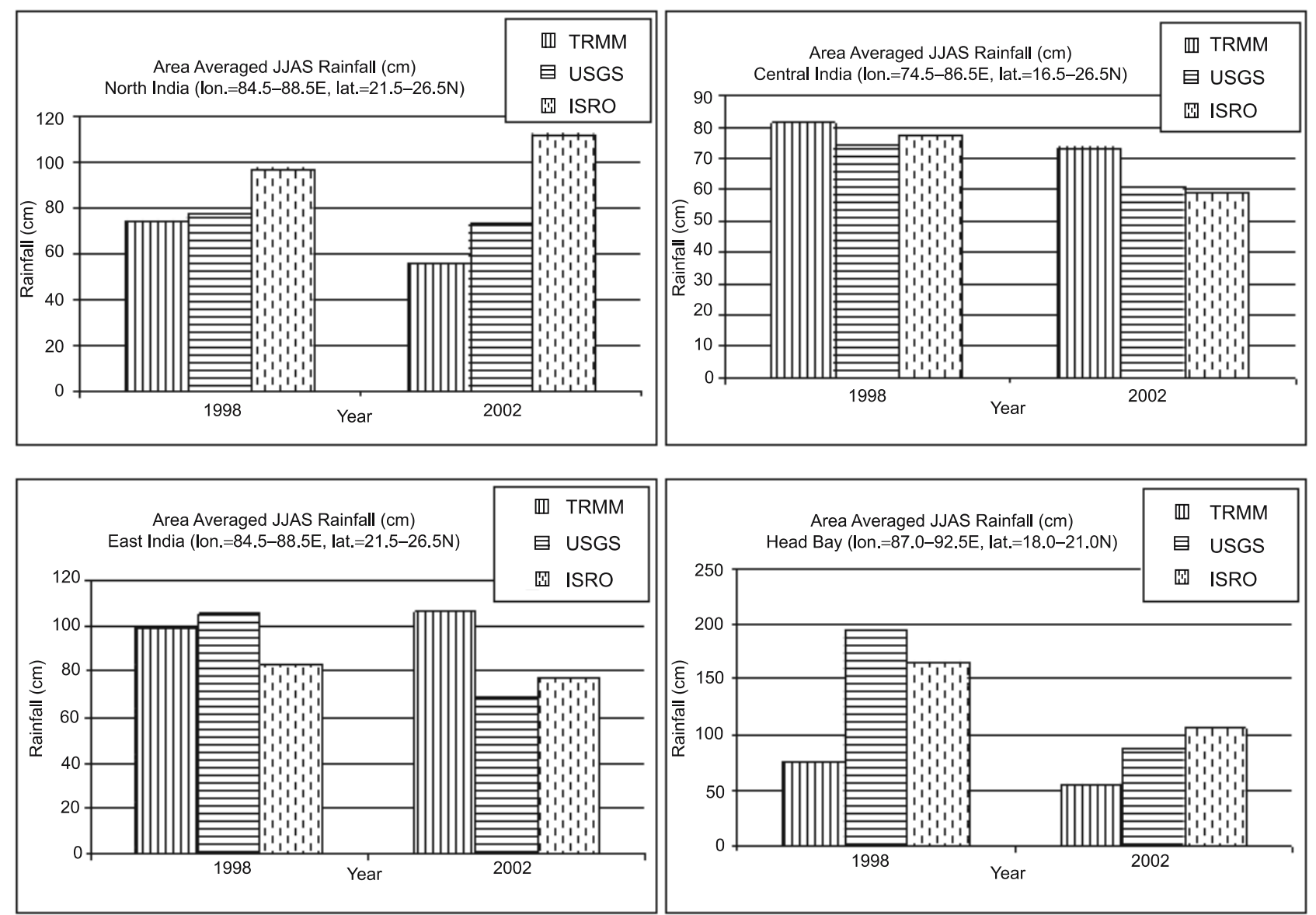

Figure 12. JJAS area averaged total rainfall $(\mathrm{cm})$ over north India and central India (upper panel) and east India and Head Bay (lower panel).

is overestimating the rainfall amounts. In both the years, simulated rainfall values are mostly in phase with those of TRMM; though out of phase relation also exist. In 2002 also, both models have overestimated the rainfall. In both 1998 and 2002, an episode of spurious rainfall is simulated by MM5USGS. With the progress of monsoon, the rainfall becomes quantitatively comparable to observation. However, it may be noted that in a seasonal simulation the models are not expected to simulate phase and amplitude of individual systems as observed.

It is also seen that in most of the cases MM5USGS has produced rainfall higher than that of MM5-ISRO. Also, it is overestimating the rainfall mean with respect to TRMM in majority of cases, including both the normal and deficient monsoon years. Perhaps, the ISRO generated vegetation has the true picture of land use and vegetation fraction as it has separate monthly vegetation fraction for every month of the two years. Whereas, the USGS generated vegetation have the same monthly values for every year. From the vegetation plots (figure 3), it is found that ISRO generated vegetation fraction is lower than the USGS mostly over north-eastern India and foothills of Himalayas and some parts of eastern India. These are the regions where the difference between the MM5-USGS and MM5-ISRO simulated rainfall amounts are markedly visible from the rainfall plots. Over rest of India, ISRO vegetation fraction is higher than USGS vegetation fraction.

Table 2 presents the All India seasonal (JJAS) mean rainfall and standard deviation for the years 1998 to 2002. Standard deviation is the measure of dispersion in a series of observations. Results indicate that standard deviation of MM5-ISRO is closer to TRMM in 1998 and 2001 whereas MM5USGS is closer in 1999, 2000 and 2002. All India JJAS rainfall mean by MM5-ISRO is in proximity to that captured by TRMM for all the years except 1999. In majority of the years MM5-USGS has higher standard deviation and JJAS rainfall mean. Higher standard deviation of MM5-USGS indicates that the USGS vegetation induces dispersive effect leading to higher standard deviation in the model simulated rainfall.

Root mean square error (abbreviated as RMSE) is the measure of the differences between the values predicted by a model or an estimator and the values actually observed from the thing being modeled 

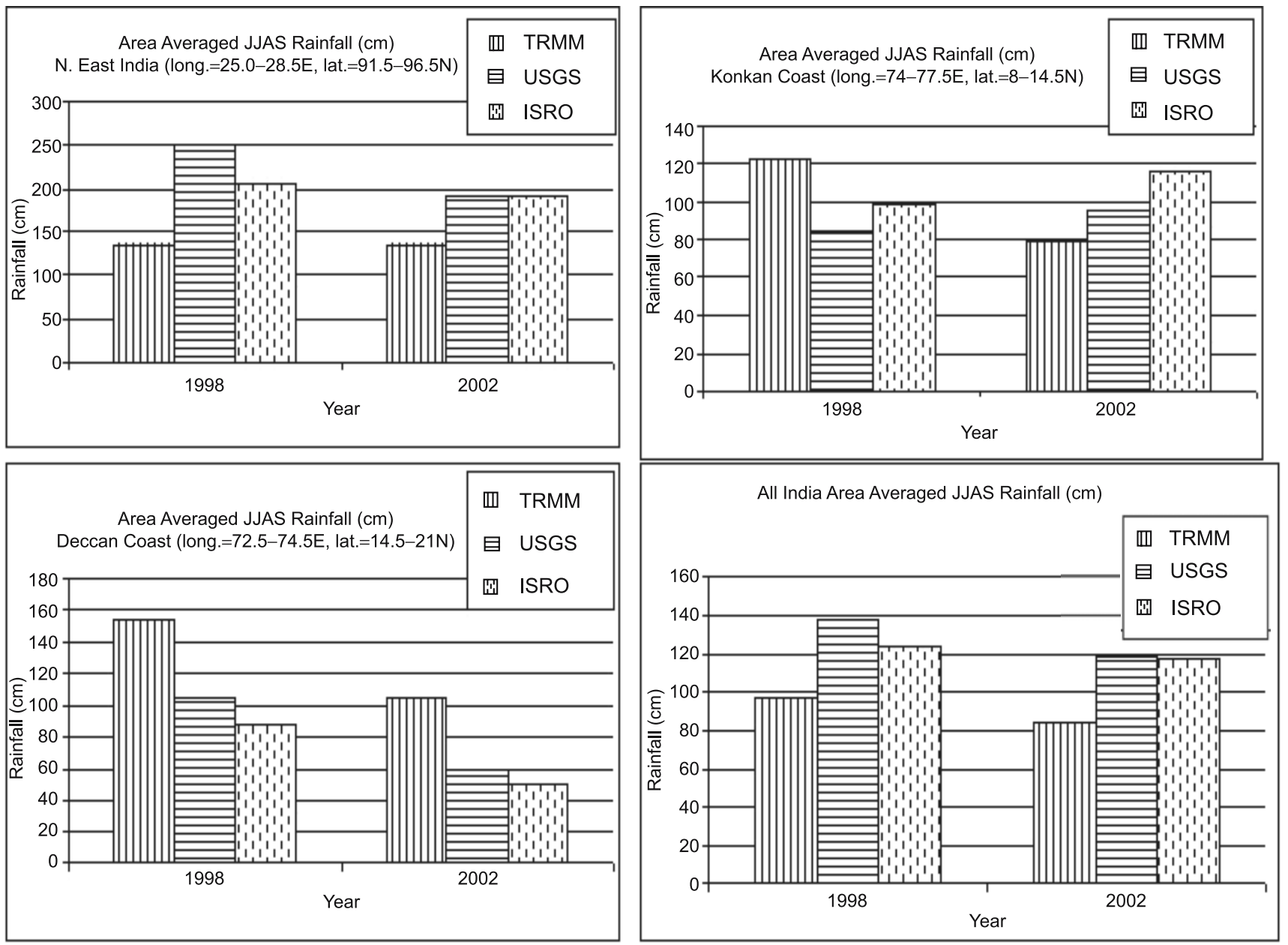

Figure 13. JJAS area averaged total rainfall $(\mathrm{cm})$ over northeast India and Konkan coast (upper panel) and Deccan coast and over All-India (lower panel).

or estimated. Figure 15 shows the histogram plot of the model biases and RMSE for 1998 and 2002. Figures 16 and 17 present the model biases and RMSE, respectively for the years 1999-2001. Bias is defined as the ratio of the model simulated value to the observed value. If the bias is less than 1 , it implies that the model is underestimating and if greater than 1, it indicates that model is overestimating the value.

From figure 15, it is seen that RMSE of All India total rainfall for MM5-ISRO is lesser in the months of June and July, and JJAS for both the years 1998 and 2002. MM5-USGS on the other hand has lesser RMSE in the months of August and September for the years 1998 and 2002. The same relation is seen from figure 15 for the model biases. MM5-ISRO shows better simulation in the months of June and July, and JJAS (for 1998 and 2002) whereas MM5-USGS is better in the months of August and September for both the years. From the histogram plot of the model biases it is also seen that MM5 simulations using USGS vegetation has a greater tendency of overestimation than the simulations using ISRO vegetation. This is confirmed by the higher All India JJAS rainfall by MM5-USGS. With respect to RMSE and bias, performance of MM5-USGS is in edge over MM5ISRO for the years 1999-2001 (figures 16 and 17). July and JJAS RMSE for All India rainfall is mostly lower for MM5-ISRO. Also, it is seen that July and JJAS bias for the same is mostly closer to unity for MM5-ISRO.

\subsection{Wind}

It is seen that changes in land surface conditions by change in the spatial coverage of vegetation and the type of vegetation and change in the land use pattern influences the atmospheric circulation. Land surface characteristics are also important contributing factors. This happens due to modification of the surface energy balance and hydrological cycle. Rowell and Blondin (1990) showed that the 5-day weather forecast for West Africa from ECMWF operational forecasting model was sensitive to the surface moisture distribution. 
All India Daliy Area Averaged Rainfall ( $\mathrm{mm}$ )
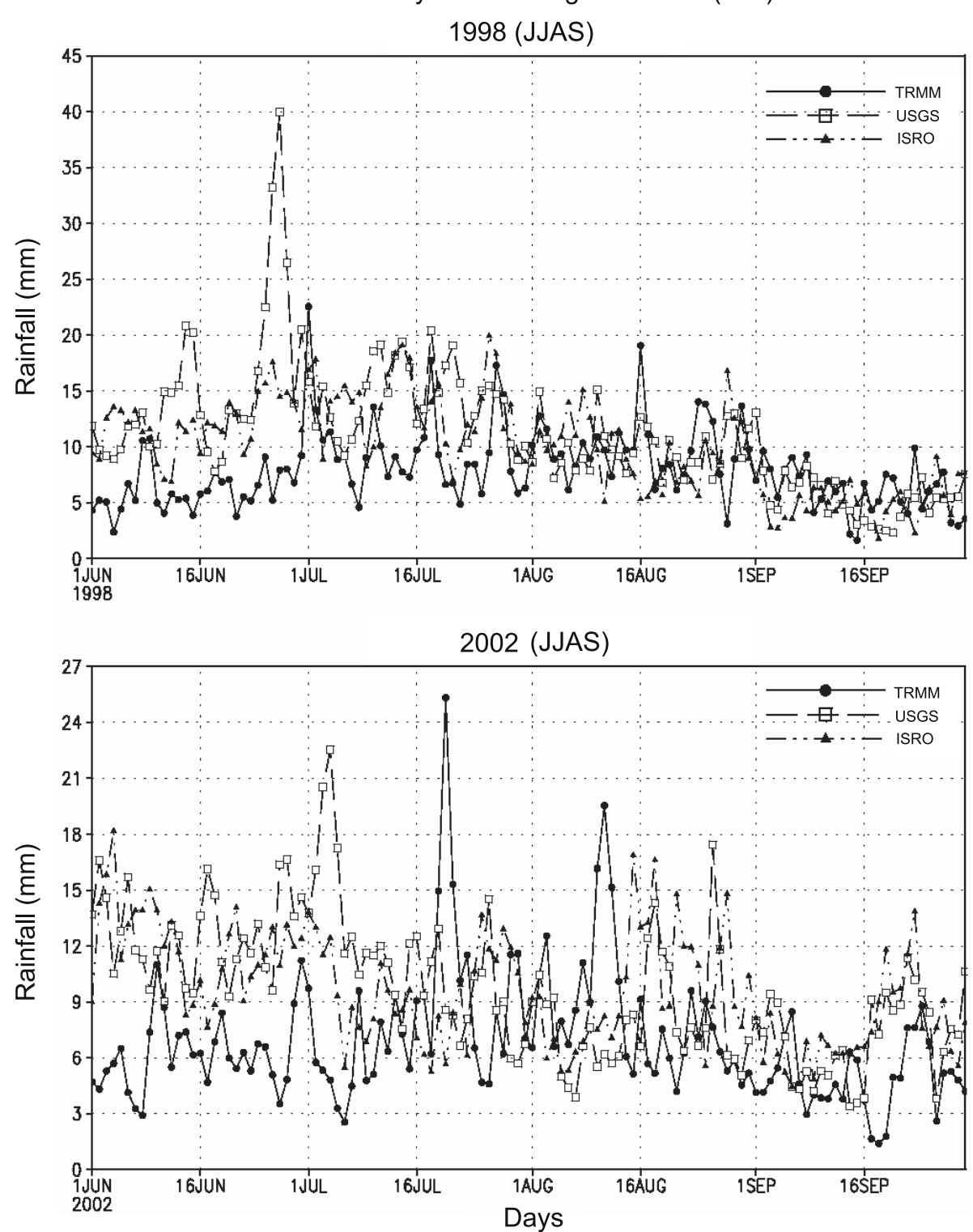

Figure 14. Time series of model simulated and TRMM All-India daily area averaged rainfall for the years 1998 (upper panel) and 2002 (lower panel).

Table 2. All India seasonal (JJAS) mean rainfall $(\mathrm{mm})$ and standard deviation $(\mathrm{mm} /$ day).

\begin{tabular}{|c|c|c|c|c|c|c|c|c|c|c|}
\hline & \multicolumn{2}{|c|}{1998} & \multicolumn{2}{|c|}{1999} & \multicolumn{2}{|c|}{2000} & \multicolumn{2}{|c|}{2001} & \multicolumn{2}{|c|}{2002} \\
\hline & Mean & S D & Mean & S D & Mean & S D & Mean & S D & Mean & S D \\
\hline TRMM & 7.972 & 3.41 & 7.255 & 3.72 & 7.519 & 3.13 & 7.665 & 3.24 & 6.898 & 3.46 \\
\hline MM5-USGS & 11.262 & 5.74 & 8.752 & 3.26 & 10.208 & 3.22 & 8.18 & 3.59 & 9.731 & 3.70 \\
\hline MM5-ISRO & 10.096 & 4.18 & 9.006 & 4.40 & 9.978 & 4.04 & 7.341 & 3.35 & 9.633 & 3.04 \\
\hline
\end{tabular}

The cross equatorial flow and Somali jet over the northern coast of Somali are the two important synoptic features of the Indian summer monsoon. Somali jet is a belt of persistent strong southwesterly wind flow, which is also referred to as the low level jet. During July, the average wind speed of the jet is about $22-33$ knot and is greater than 34 knot about $20 \%$ of the time. Development of a highpressure zone over the Tibet, also known as the Tibetan High, is an important part of the monsoon systems. Monsoon flow depends on the strengthening or weakening of the Tibetan anticyclone. 

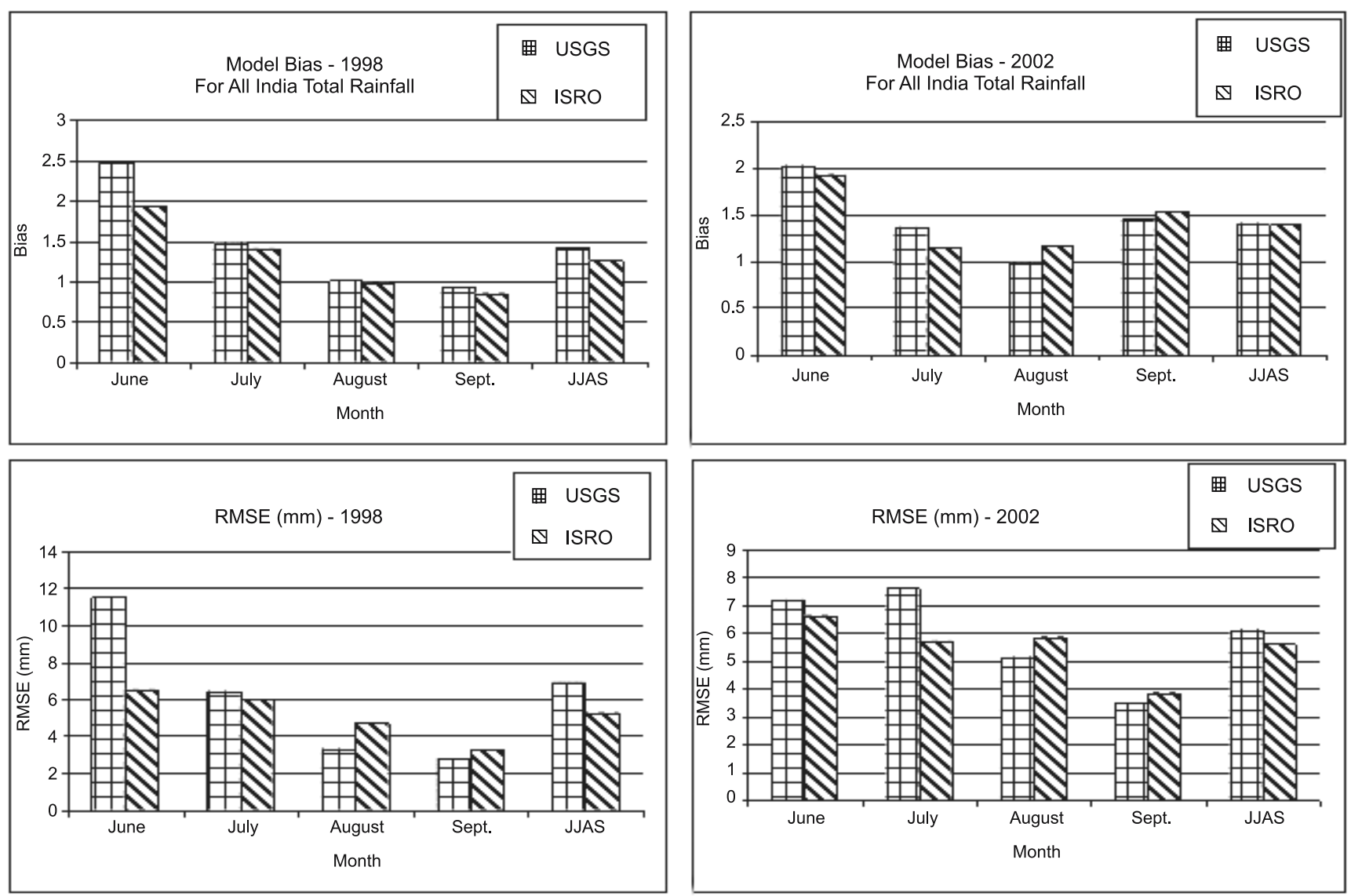

Figure 15. Model bias (upper panel) and root mean square error (mm) (lower panel) of MM5 simulations with respect to TRMM.

Other than Tibetan anticyclone, upper air tropical easterly jet stream over peninsular India is also an important synoptic feature characterizing the southwest monsoon over India.

In this section, we have discussed the analysed and simulated wind flow pattern at $850 \mathrm{hPa}$ and $200 \mathrm{hPa}$, considered to be representative of lower and upper atmosphere, respectively. The simulated winds of MM5 have been discussed for domain 1 (90 km resolution) in order to capture the cross-equatorial flow and Somali jet. For brevity only mean wind fields for the month of July are described here for the years 1998 and 2002.

Figure 18 displays the 850 and $200 \mathrm{hPa}$ analysed wind fields of NCEP reanalysis-II for the years 1998 and 2002. Figures 19 and 20 do the same for the MM5 simulated wind fields. Comparison of the figures 19 and 20 with figure 18 shows that in July 1998 MM5-ISRO has simulated the spatial distribution of isotachs at $850 \mathrm{hPa}$ nearer to that of NCEP. In both the years the northward extent of $15-20 \mathrm{~m} / \mathrm{s}$ and $10-15 \mathrm{~m} / \mathrm{s}$ wind speed zone of the Somali jet are more in MM5-ISRO than in MM5USGS. The maximum wind speed at the core of the Somali jet is the same for both MM5-ISRO and USGS simulations. In July 1998, MM5-USGS has simulated $10-15 \mathrm{~m} / \mathrm{s}$ wind speed maxima zone over the northeastern India to Head Bay region. MM5-ISRO is showing the maxima in a very small area over the northeastern region of India and NCEP has no signature of such maxima over the area.

Land surface processes supported by the vegetation induce influence on atmospheric circulation by heating or cooling of the overlying air. Tibetan anticyclone during the southwest monsoon season is an example. It is the manifestation of the surface heating and is regarded as the product of the elevated heat source over Tibet. Observed changes in the precipitation are also closely linked to the atmospheric circulation, the associated moisture and heat flux.

From figures 18-20, we find that in both the years MM5-ISRO has simulated the Tibetan anticyclone closer to that of the verification analysis, i.e., NCEP-reanalysis II. Both NCEP and MM5ISRO have produced the anticyclone as a ridge over the Himalayan belt whereas MM5-USGS is showing the anticyclone in the form of a closed circulation with a defined center. In July 1998, both MM5-ISRO and NCEP are representing strong and widespread Tibetan anticyclone. 

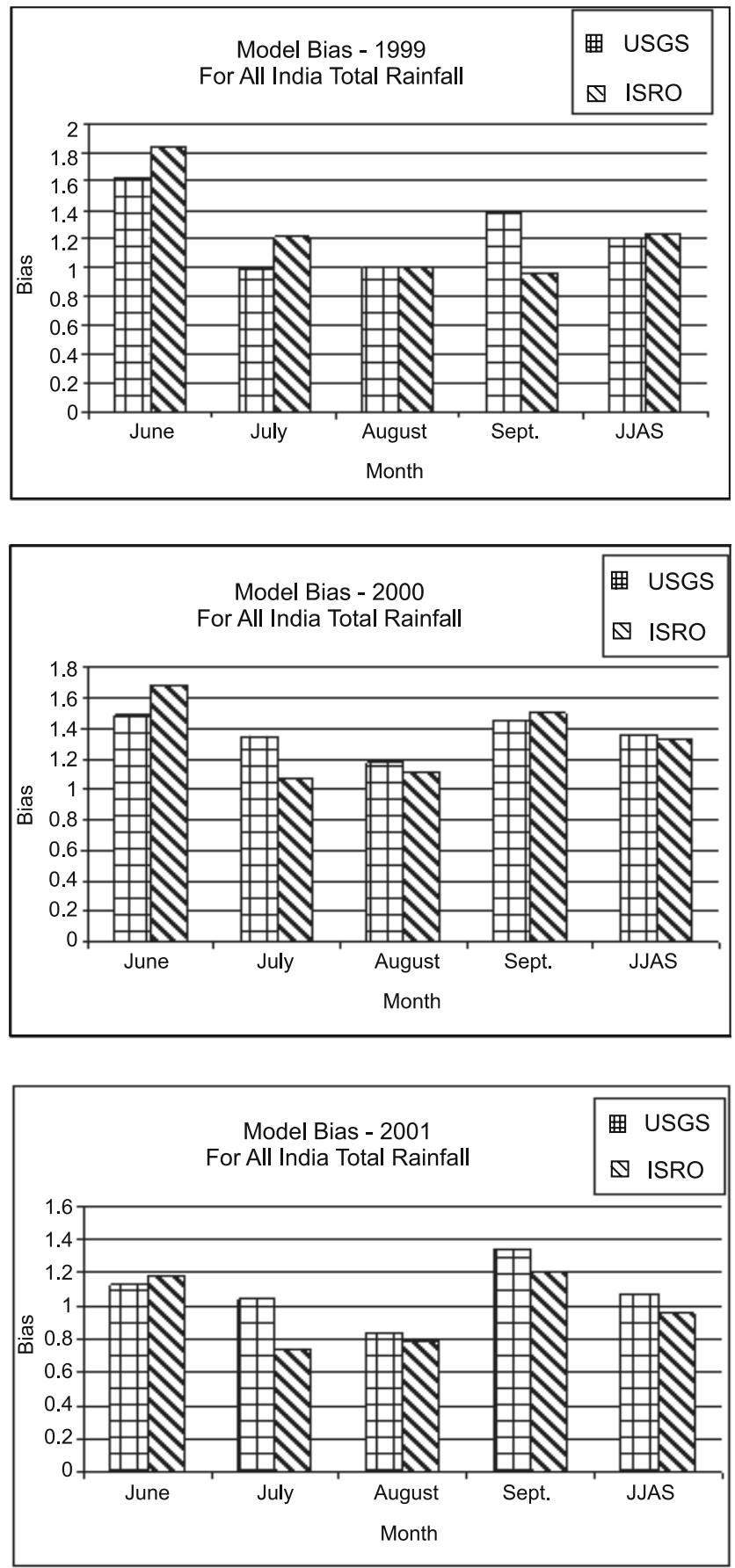

Figure 16. Model bias of MM5 simulations using USGS and ISRO generated vegetation for the years 1999, 2000 and 2001.

\subsection{Surface parameters}

Surface parameters are very important parts of the various processes that are active in the atmosphere. They serve as the major factors for the various feedback mechanisms influencing different weather events. They play a vital role in surface-to-air interaction, and are characteristic of the surface properties. Air temperature at $2 \mathrm{~m}$ above the surface, sensible and latent heat fluxes are some of
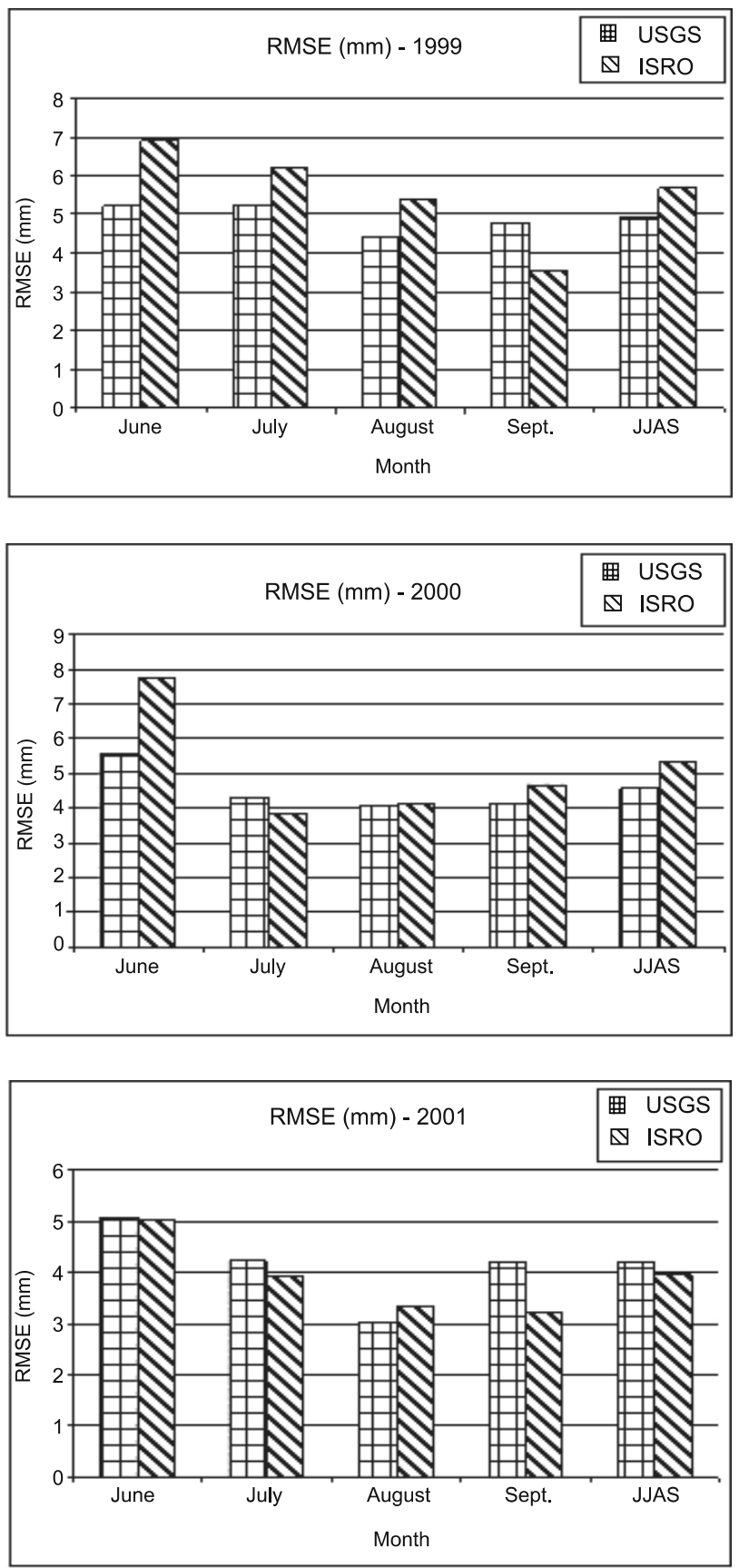

Figure 17. Root mean square error of MM5 simulations w.r.t TRMM using USGS and ISRO generated vegetation for the years 1999, 2000 and 2001.

the important surface parameters that need to be studied. For brevity, we have discussed only the temperature at $2 \mathrm{~m}$ above the ground and sensible heat fluxes for the month of July for the two contrasting monsoon years 1998 and 2002. Details of other surface parameters are discussed in Das et al (2007).

\subsubsection{2m Air temperature}

Figures 21 and 22 depict the analysed and simulated $2 \mathrm{~m}$ air temperature from NCEP reanalysis-II 
NCEP Reanalysis - Horizontal Wind - July

(a)

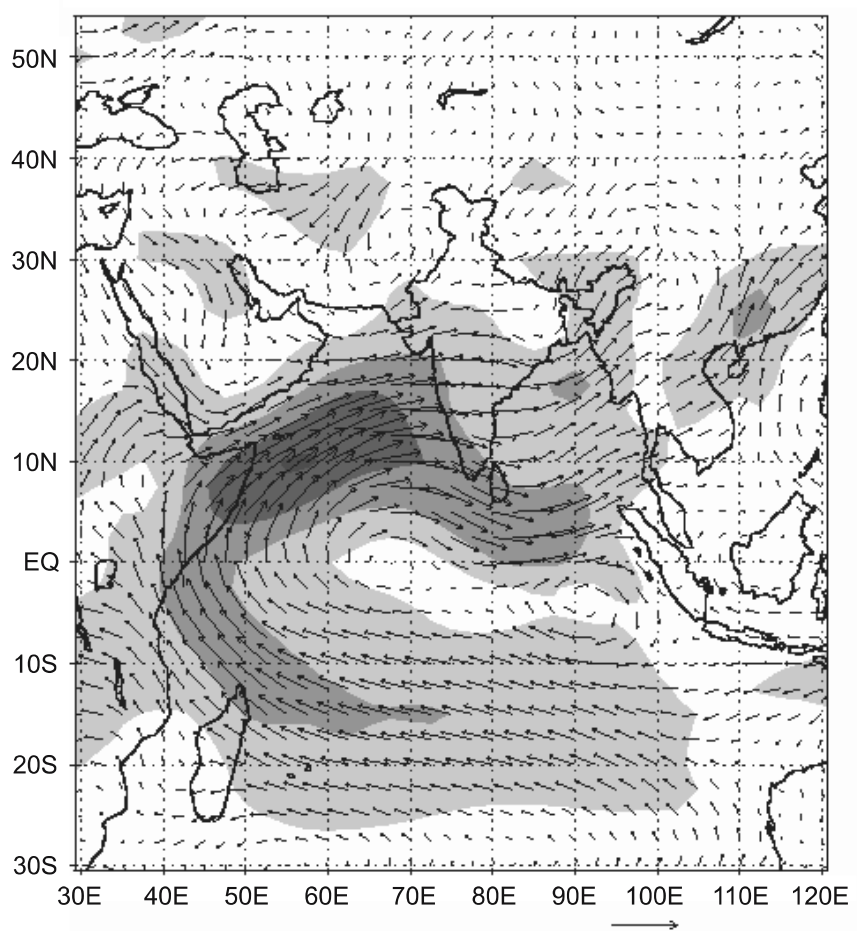

(b)

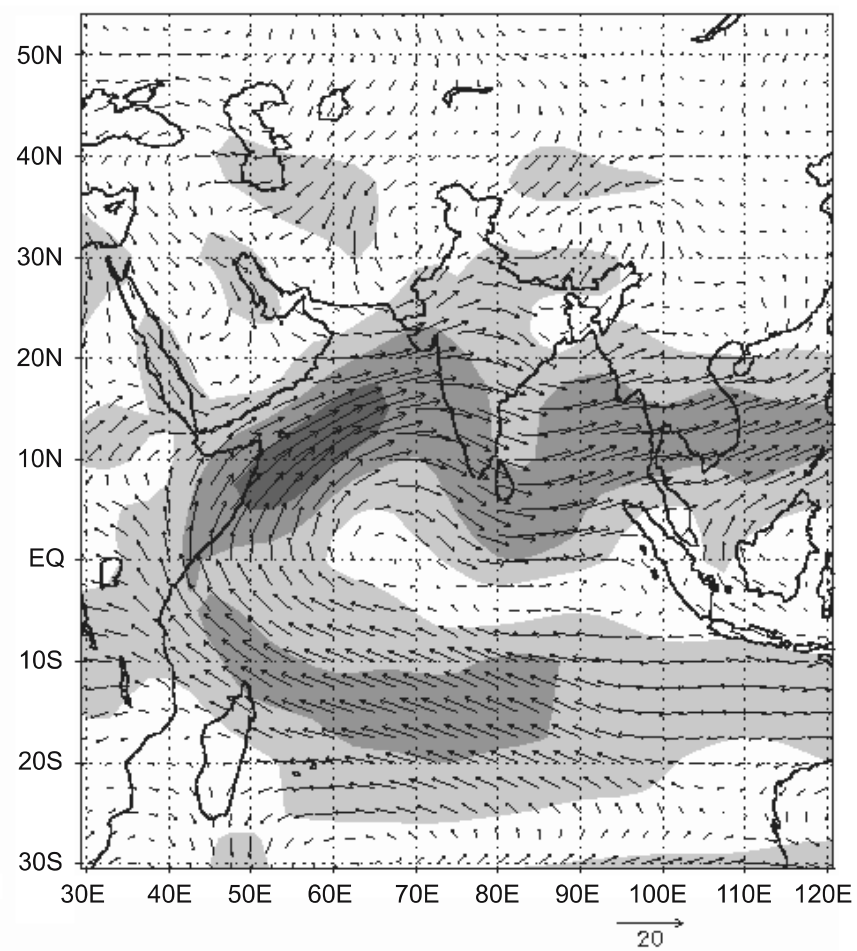

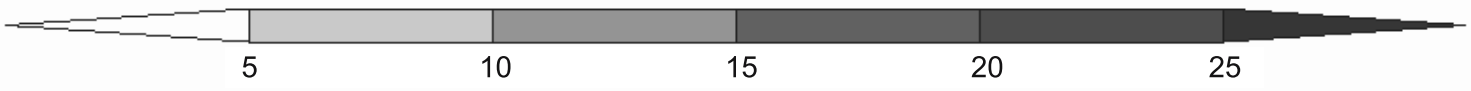

(c)

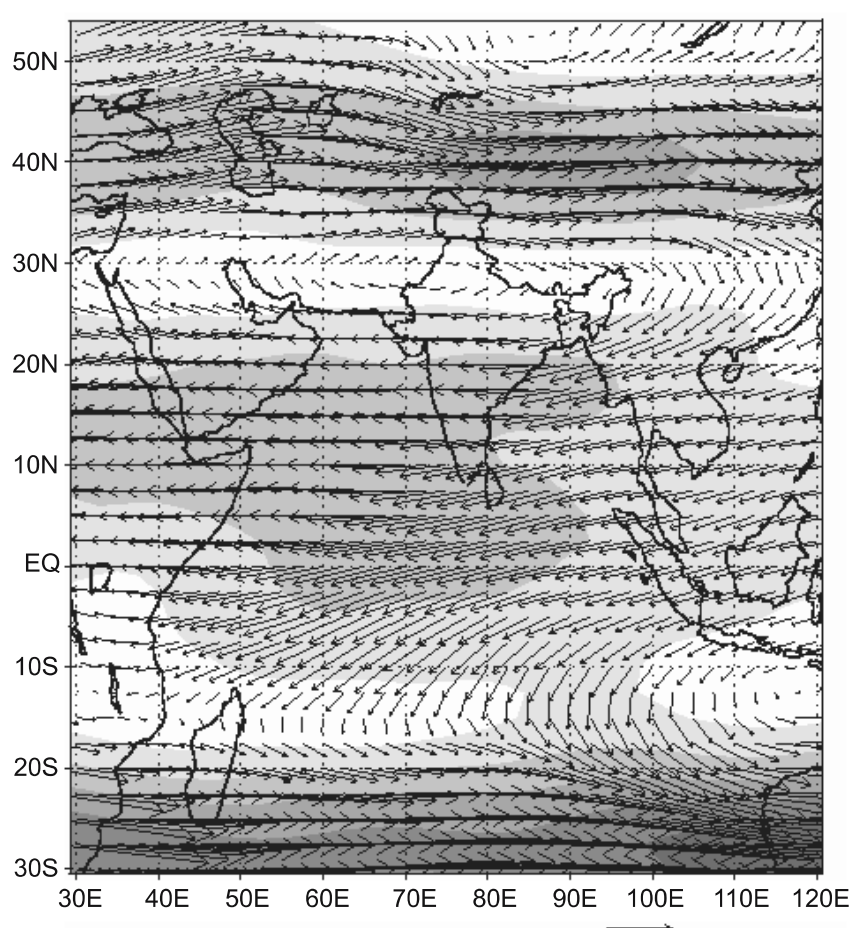

(d)

$200 \mathrm{hPa}-2002$

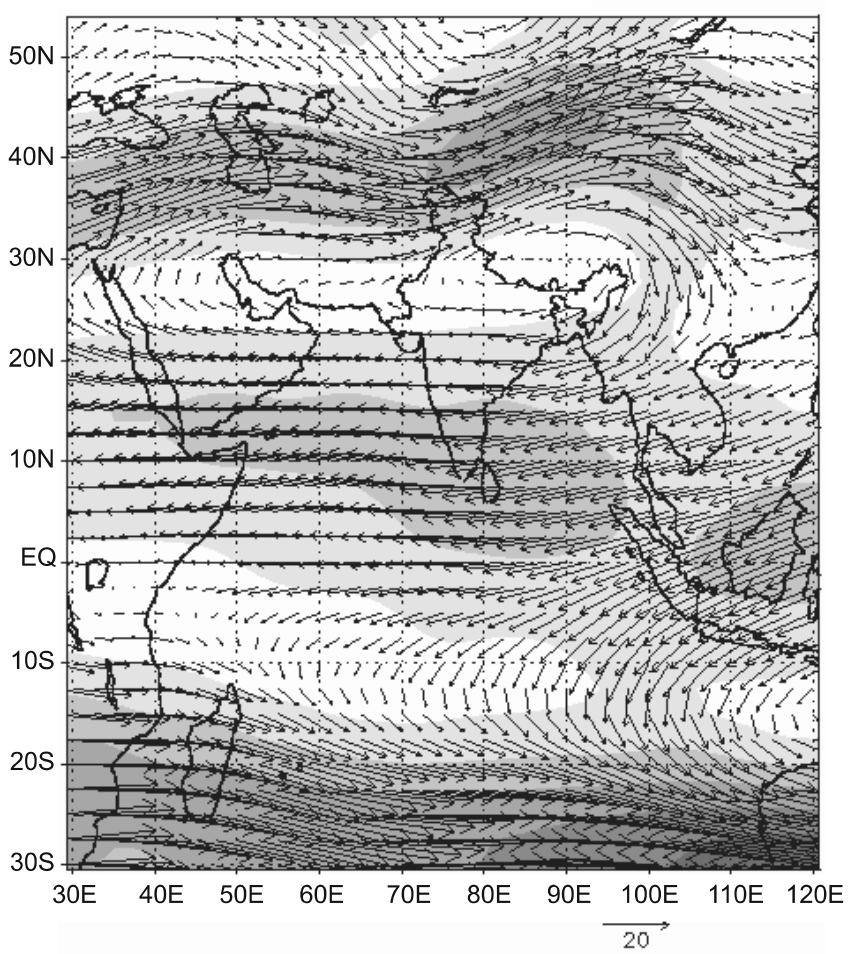

\begin{tabular}{l|l|l|l|l|llll}
\hline & & & & & & & & \\
10 & 20 & 30 & 40 & 50 & 60 & 70 & 80 & 90
\end{tabular}

Figure 18. NCEP reanalysis II mean horizontal wind (m/s) of July at $850 \mathrm{hPa}$ for (a) 1998 and (b) 2002 and at $200 \mathrm{hPa}$ for (c) 1998 and (d) 2002. Isotachs are shaded. 
MM5 Simulated Mean Horizontal Wind - July, 1998
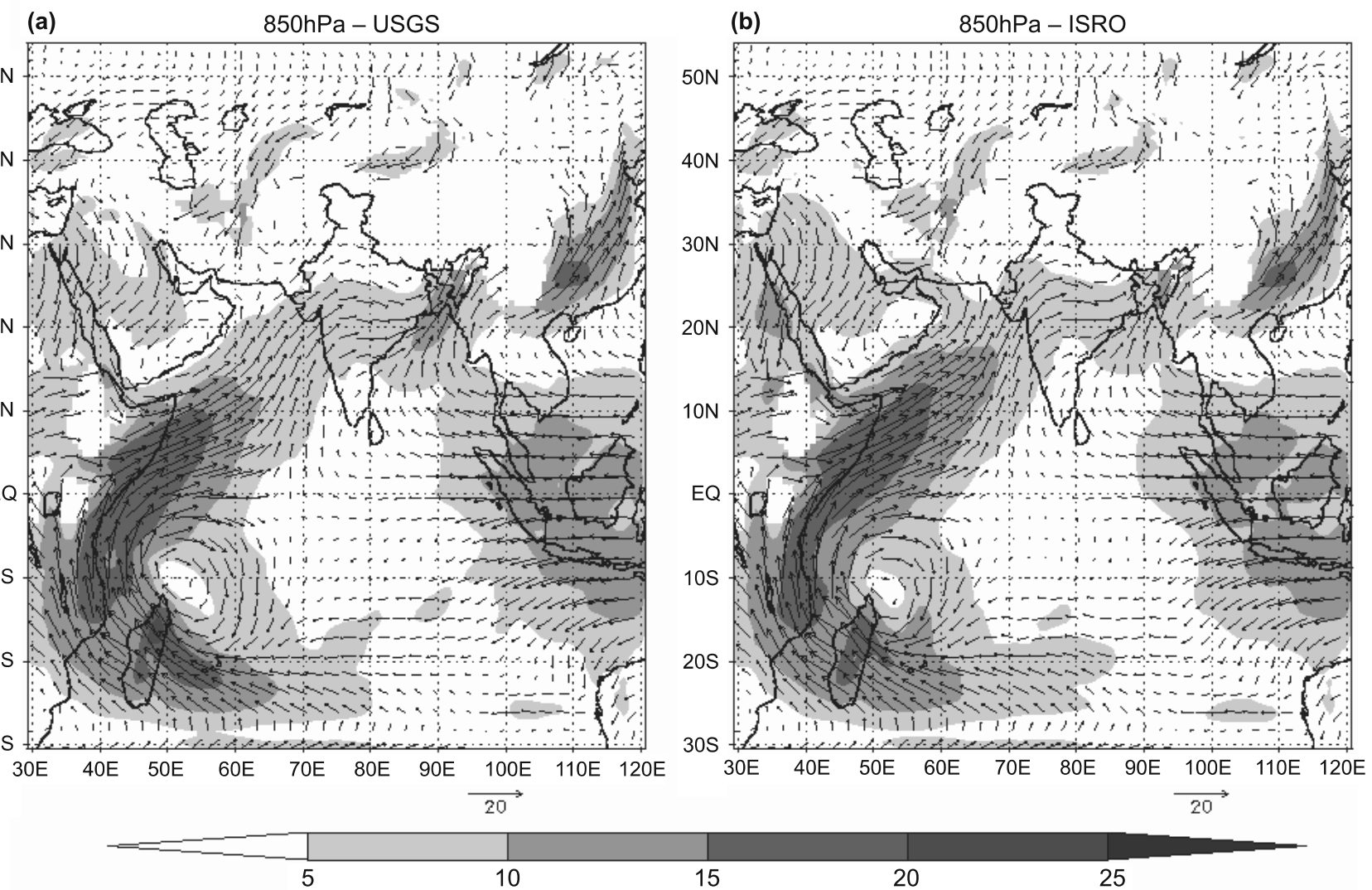

(c)

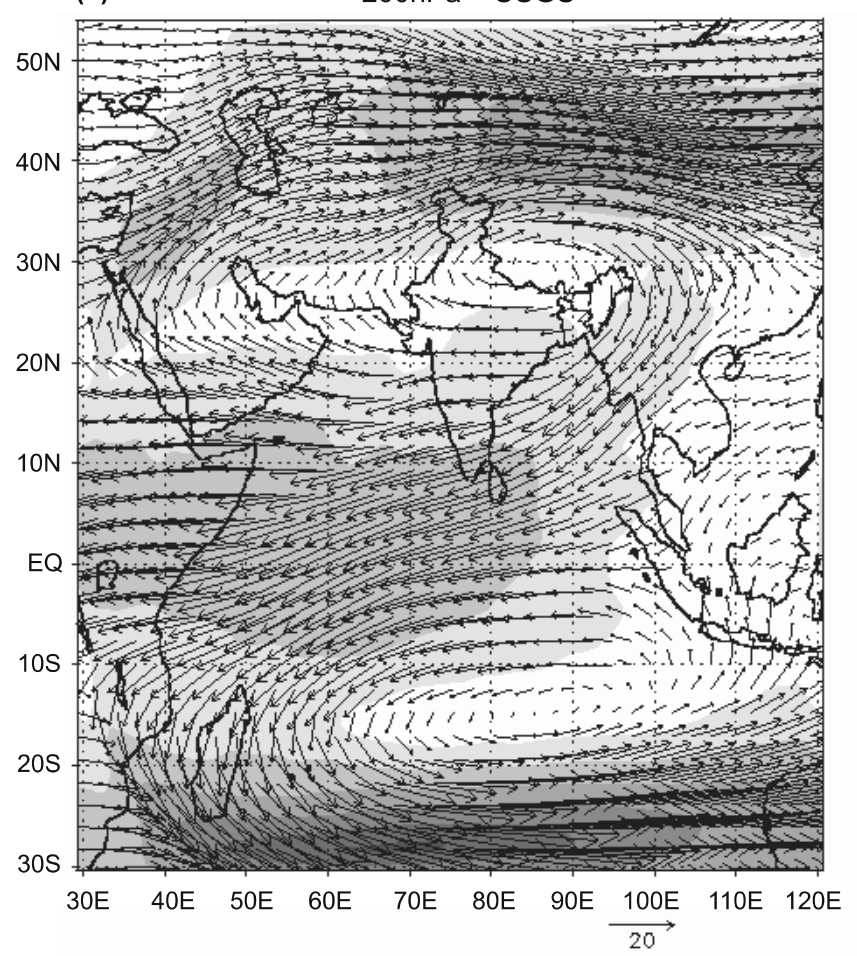

(d)

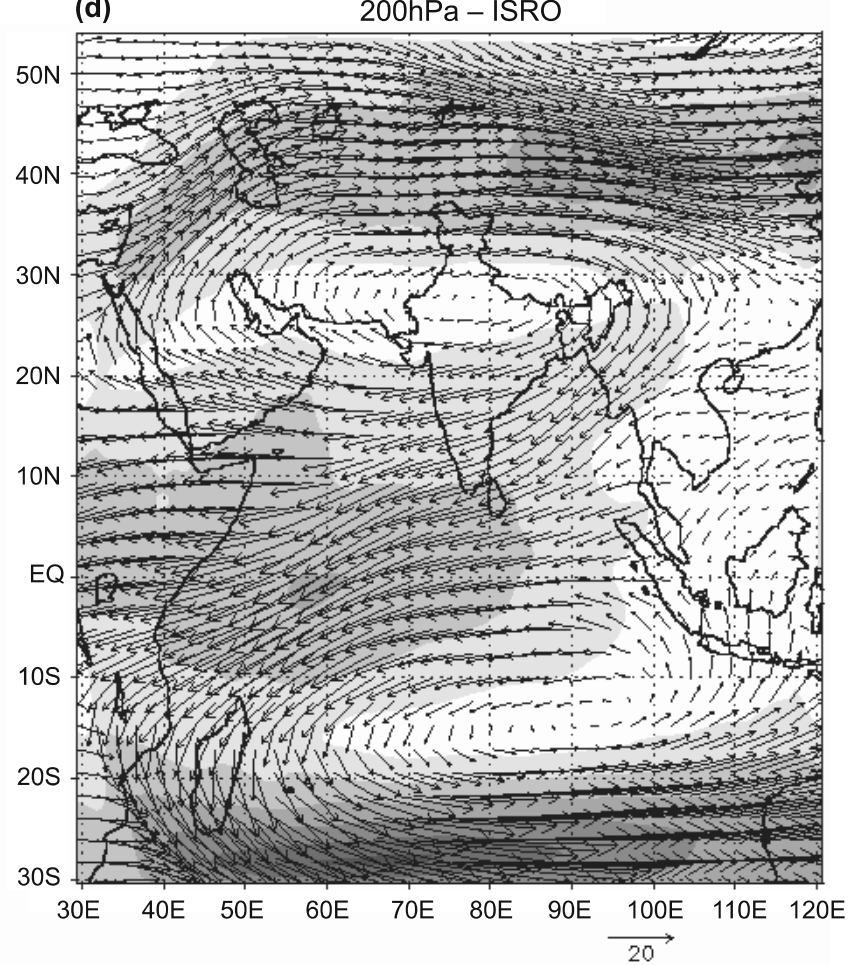

80
90

Figure 19. MM5 simulated mean horizontal wind (m/s) of July 1998 at $850 \mathrm{hPa}$ for (a) USGS and (b) ISRO and at $200 \mathrm{hPa}$ for (c) USGS and (d) ISRO. Isotachs are shaded. 
MM5 Simulated Mean Horizontal Wind - July, 2002

(a)

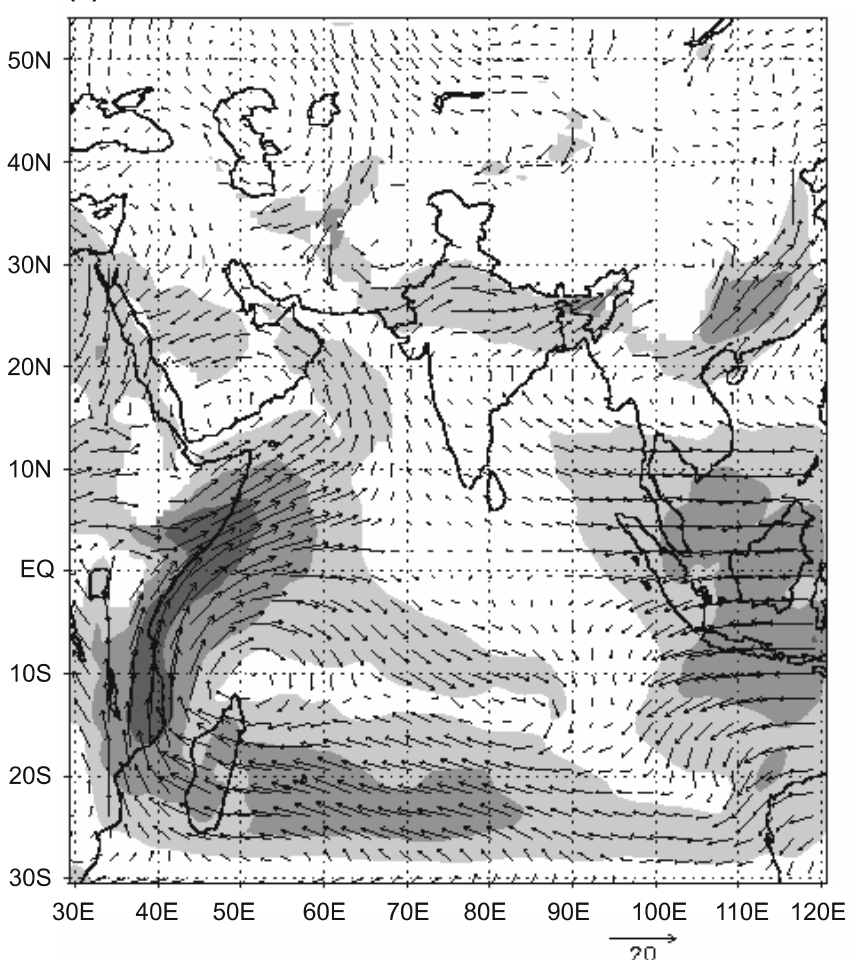

(b)

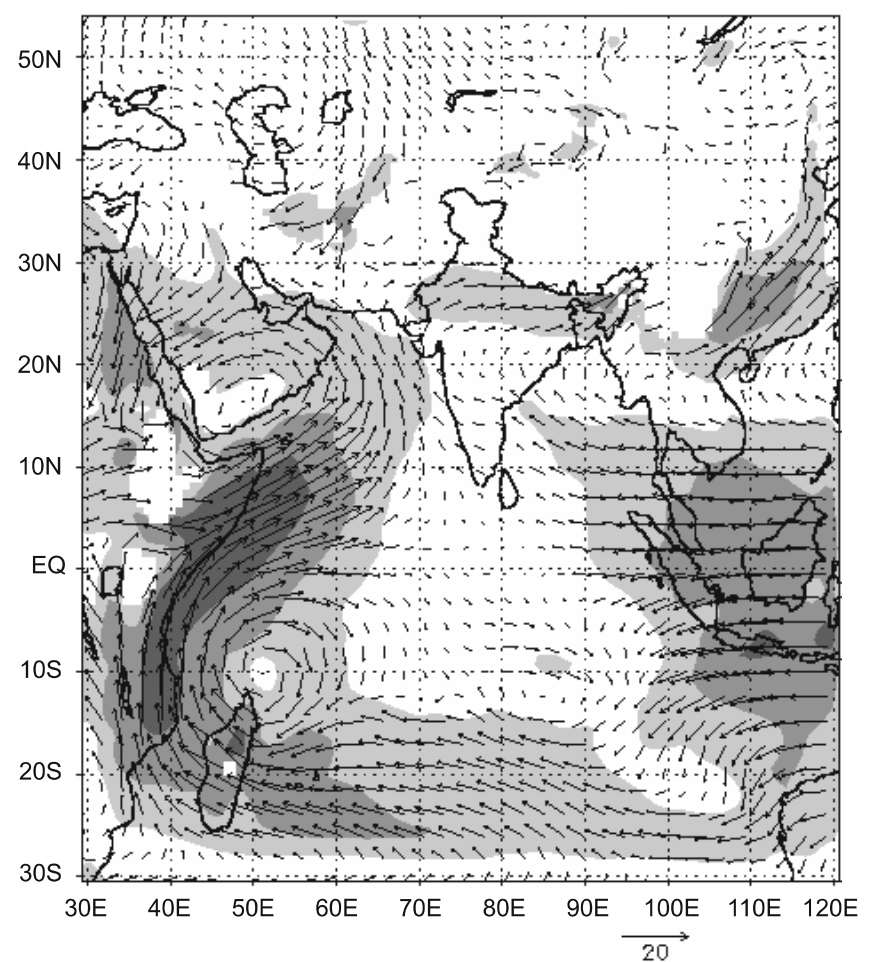

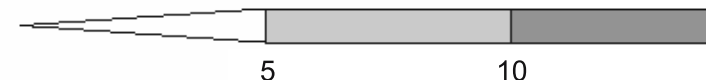

15

20

25

(d)

$200 \mathrm{hPa}-$ ISRO
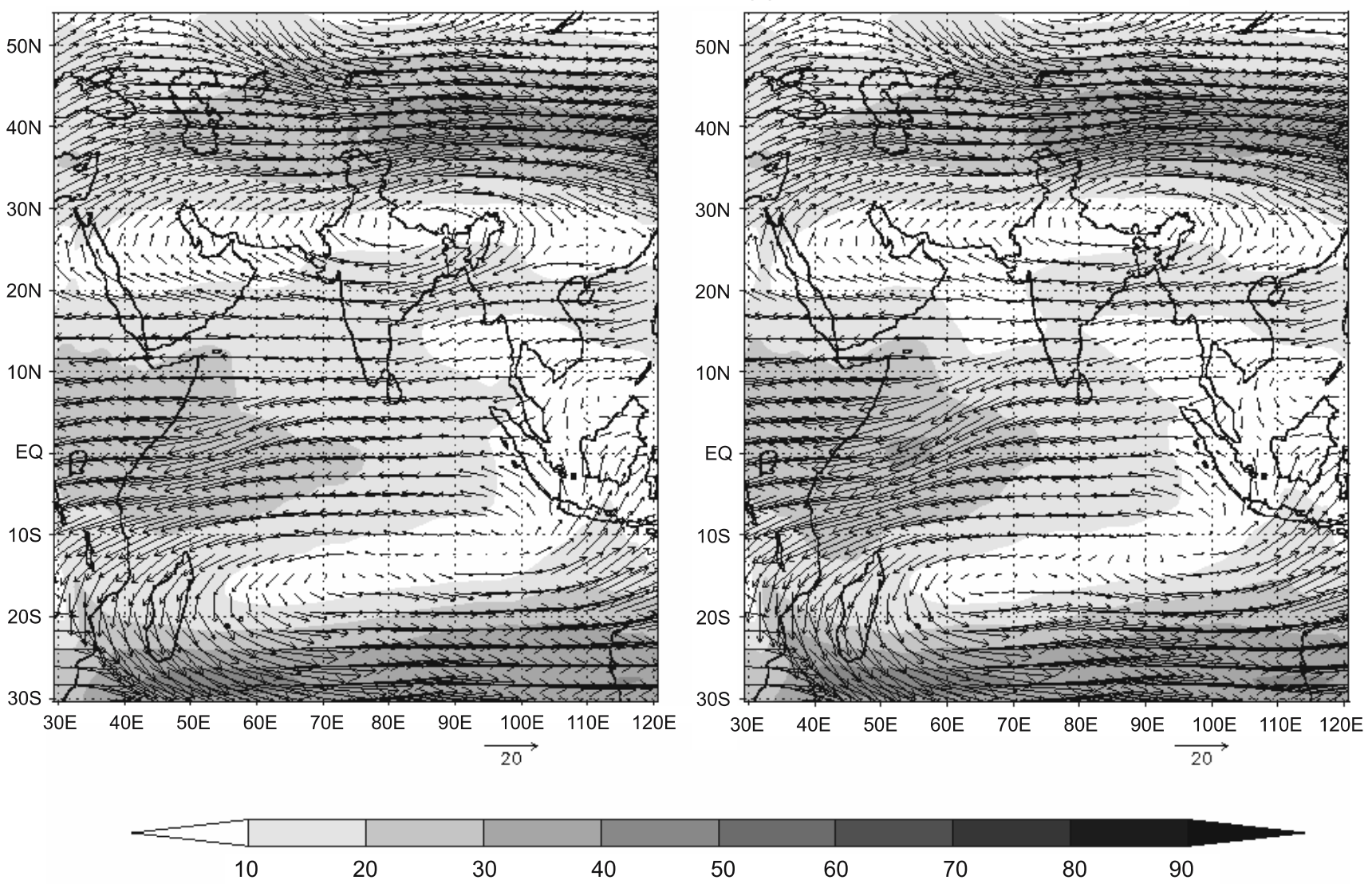

Figure 20. As in figure 13 but for July 2002. 
NCEP Reanalysis - July, 2m Air Temperature

(a) 1998

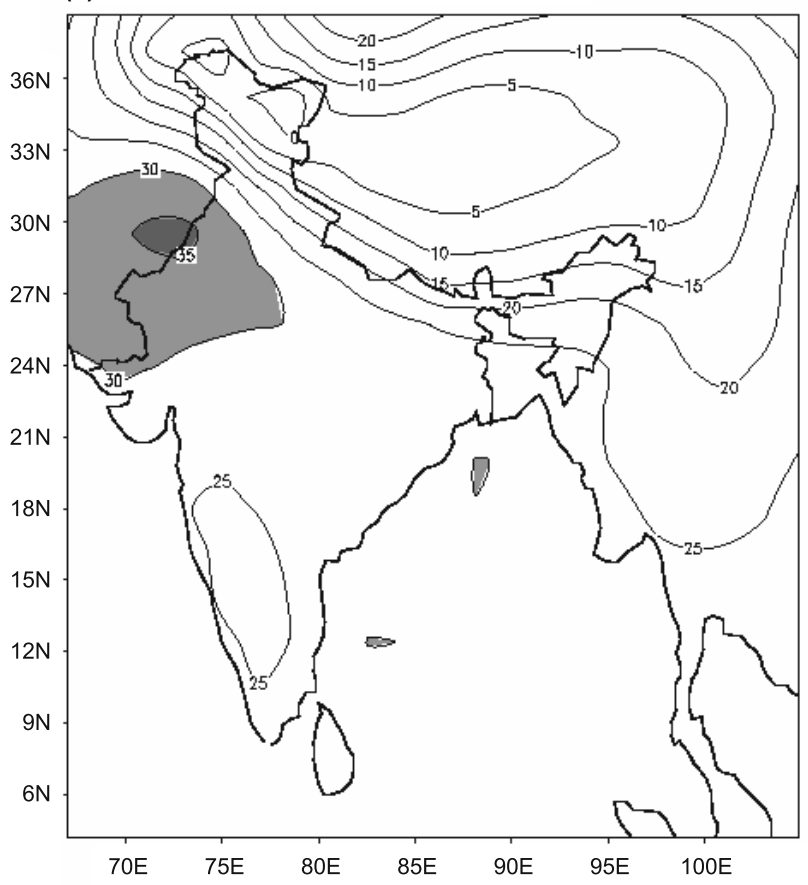

(b)

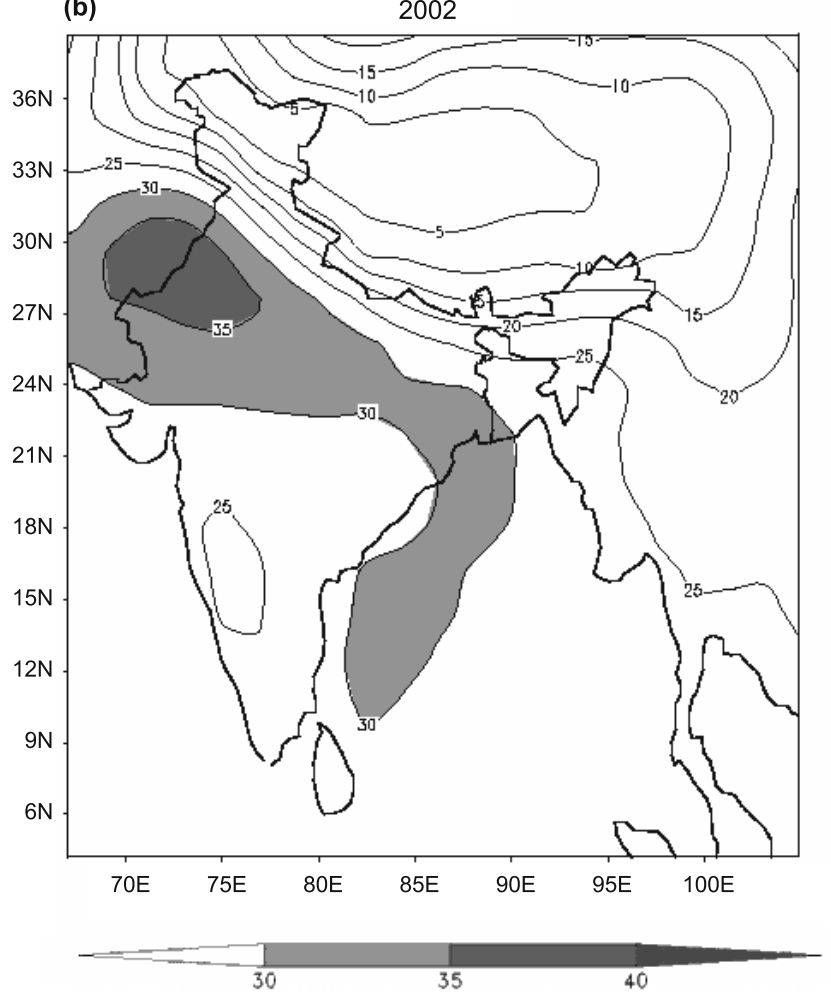

Figure 21. NCEP reanalysis II $-2 \mathrm{~m}$ air temperature $\left({ }^{\circ} \mathrm{C}\right)$ averaged for the month of July (a) 1998 and (b) 2002.

and MM5, respectively. MM5 simulations using both USGS and ISRO generated vegetation have produced the $2 \mathrm{~m}$ air temperature closer to the observations in both 1998 and 2002. MM5-USGS is seen to be scoring over MM5-ISRO. In 1998 though both have failed to produce the maxima of $35^{\circ} \mathrm{C}$, the spatial extent of $30^{\circ} \mathrm{C}$ temperature in $\mathrm{MM} 5$ USGS is closer to that of the verification analysis. In 2002, MM5-USGS has simulated the maxima present in NCEP.

Over northeastern region of India, MM5-ISRO is showing greater spatial variability in the $2 \mathrm{~m}$ air temperatures than MM5-USGS. Northeastern India being a region of hilly terrain with good coverage of vegetation, greater spatial variation of $2 \mathrm{~m}$ air temperature over the region is expected compared to the other parts. So, over this region ISRO vegetation is seen to have a positive impact, reflecting the scenario observed in reality.

\subsubsection{Sensible heat flux}

Sensible heat flux is an important parameter characterizing the heat budget at the surface. It represents the amount of heat released by the surface and thus, also provides a measure of insolation. Sensible heat flux from NCEP reanalysis-II and MM5 simulations are depicted in figures 23 and 24, respectively, for the years 1998 and 2002.

In July 1998, MM5 simulations (figure 23) are unable to produce the negative zones over north India, western coast and over the eastern portion of the Indian domain that are seen in the NCEP reanalysis-II. Forecast based on USGS vegetation has simulated closer to the observation over northwest India. In July 2002 also, MM5 (figure 24) is unable to simulate the negative regions that are present in the verification analysis. Over northwest India USGS forecast is closer to observation, while others have highly underestimated the values.

\section{Concluding remarks}

Study of rainfall simulations by MM5 model using the USGS and ISRO vegetation show mixed results. The ISRO vegetation performed better over northeastern India and along the western coast. The MM5-USGS has greater tendency of overestimation of rainfall. Among the five years of study, it is seen that the RMSE of July and JJAS for All India rainfall is mostly lower for MM5ISRO. Also, the bias of July and JJAS for the same is mostly closer to unity for MM5-ISRO. However, the JJAS total rainfall over north India and Deccan coast is better simulated using the USGS vegetation. The wind fields at $850 \mathrm{hPa}$ and $200 \mathrm{hPa}$ are also better simulated by MM5 using ISRO vegetation. The synoptic features like Somali jet and Tibetan anticyclone are simulated closer to the verification analysis by MM5-ISRO. 
(a)

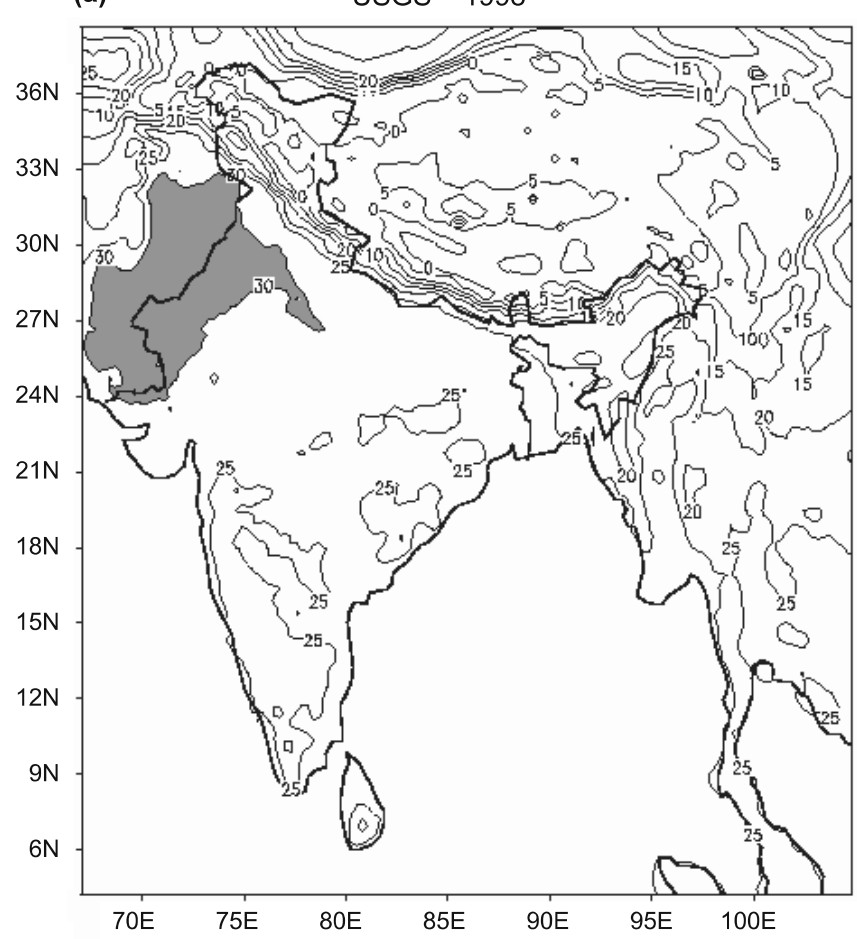

(c)

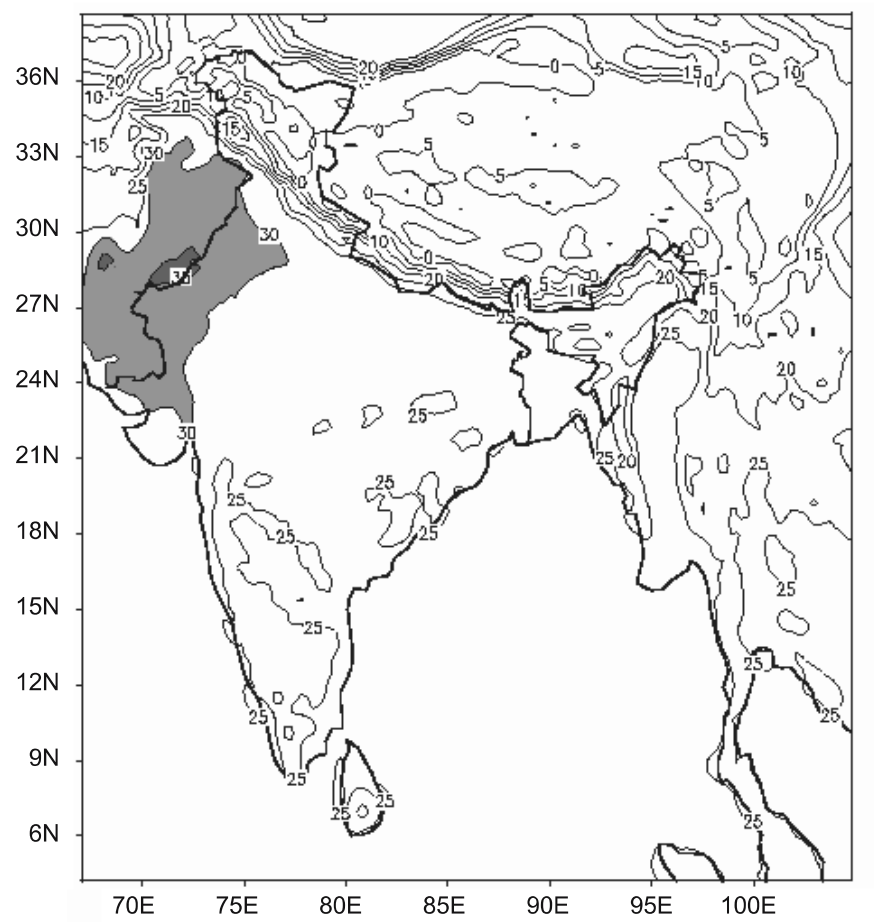

(b)

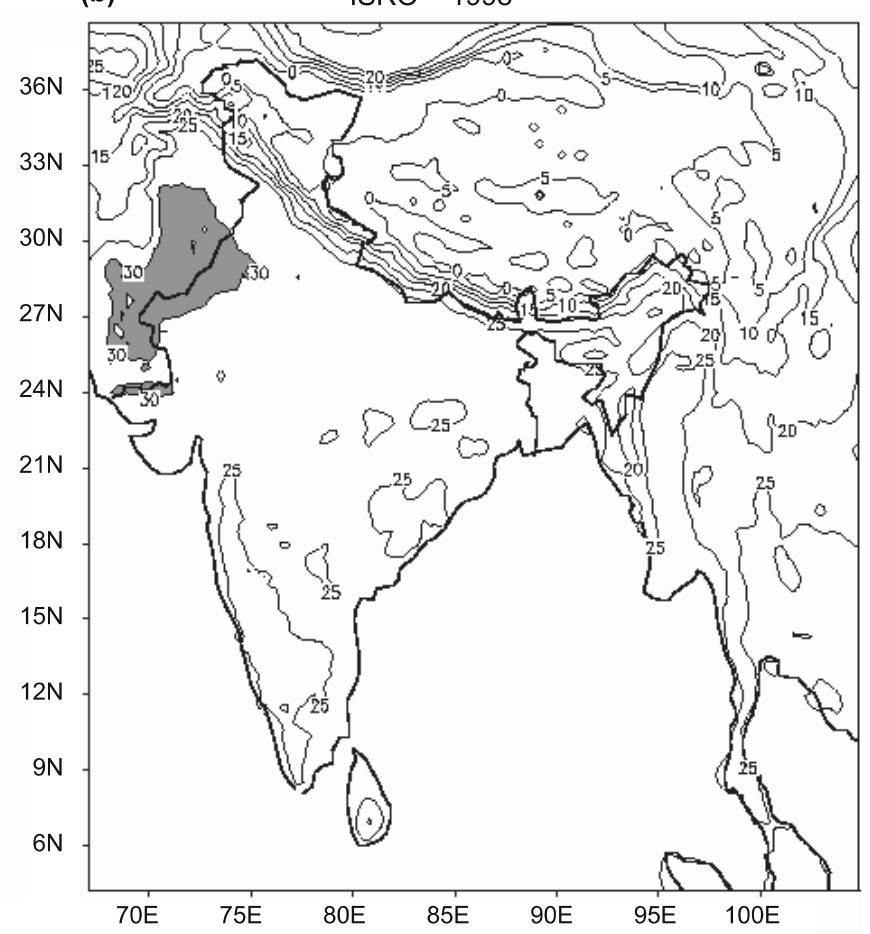

(d)

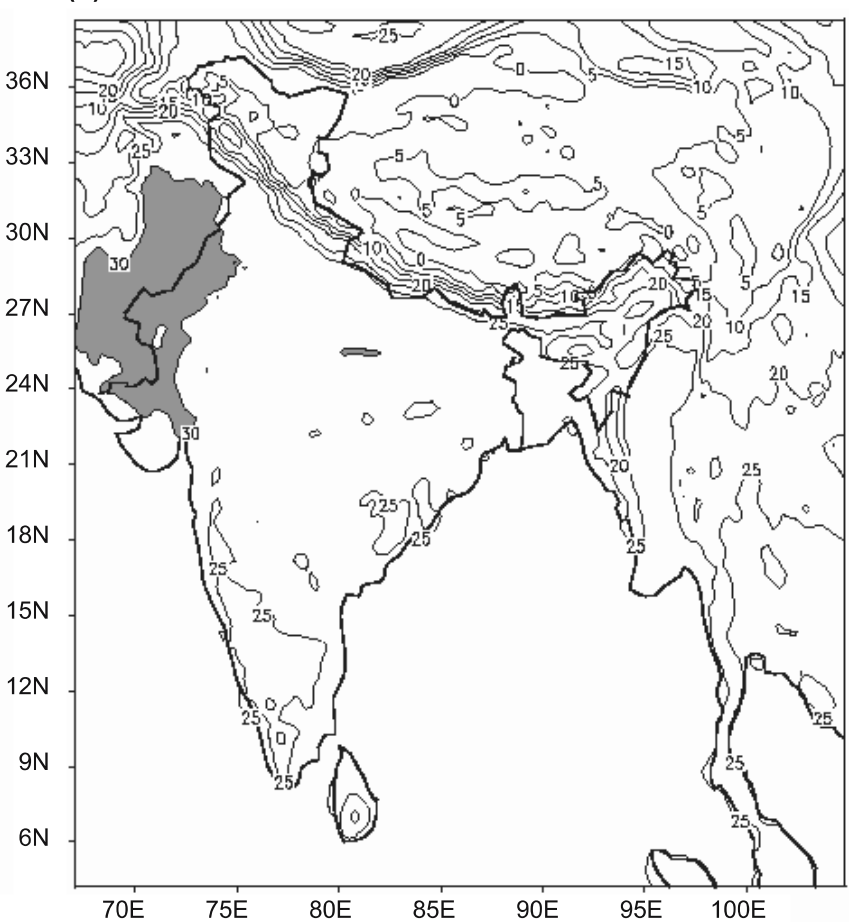

30

Figure 22. MM5 simulated $2 \mathrm{~m}$ air temperature $\left({ }^{\circ} \mathrm{C}\right.$ ) averaged for the month of July (a) USGS-1998, (b) ISRO-1998, (c) USGS-2002 and (d) ISRO-2002. 
The study shows that by changing the type of vegetation fraction in a mesoscale model, significant changes in rainfall and wind field simulations are observed. However, the results do not show

Sensible Heat Flux - July, 1998

(a)

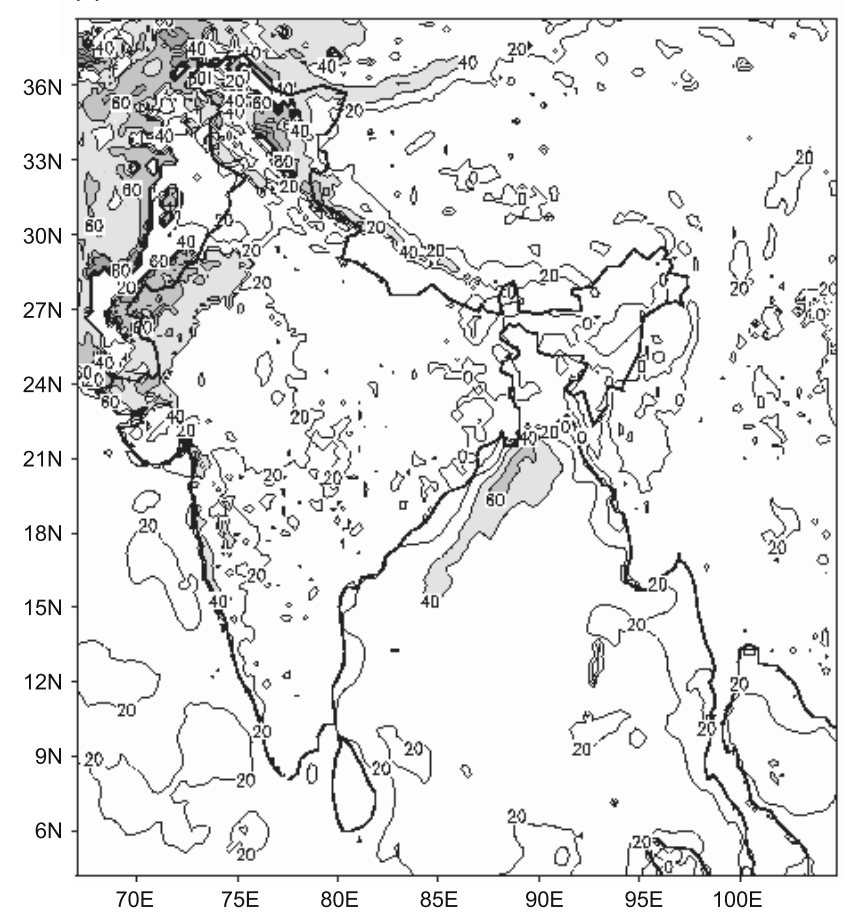

(b)

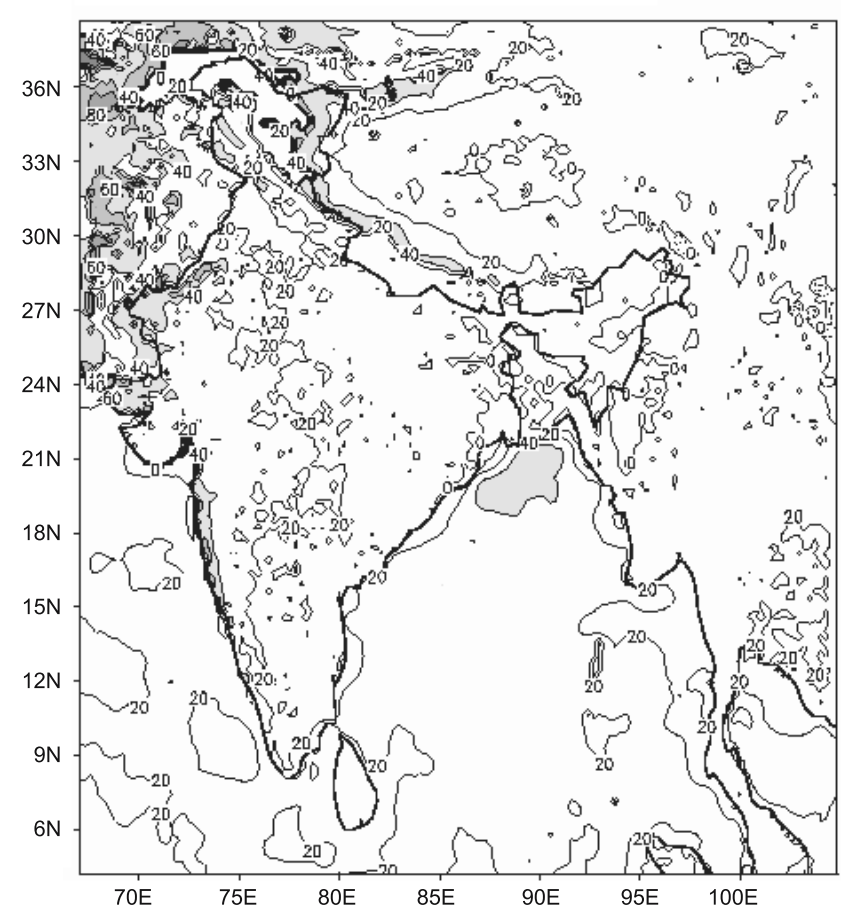

Figure 23. Sensible heat flux $\left(\mathrm{W} / \mathrm{m}^{2}\right)$ for July 1998 (a) MM5-USGS, (b) MM5-ISRO and (c) NCEP reanalysis-II. (c)

NCEP REANALYSIS-II

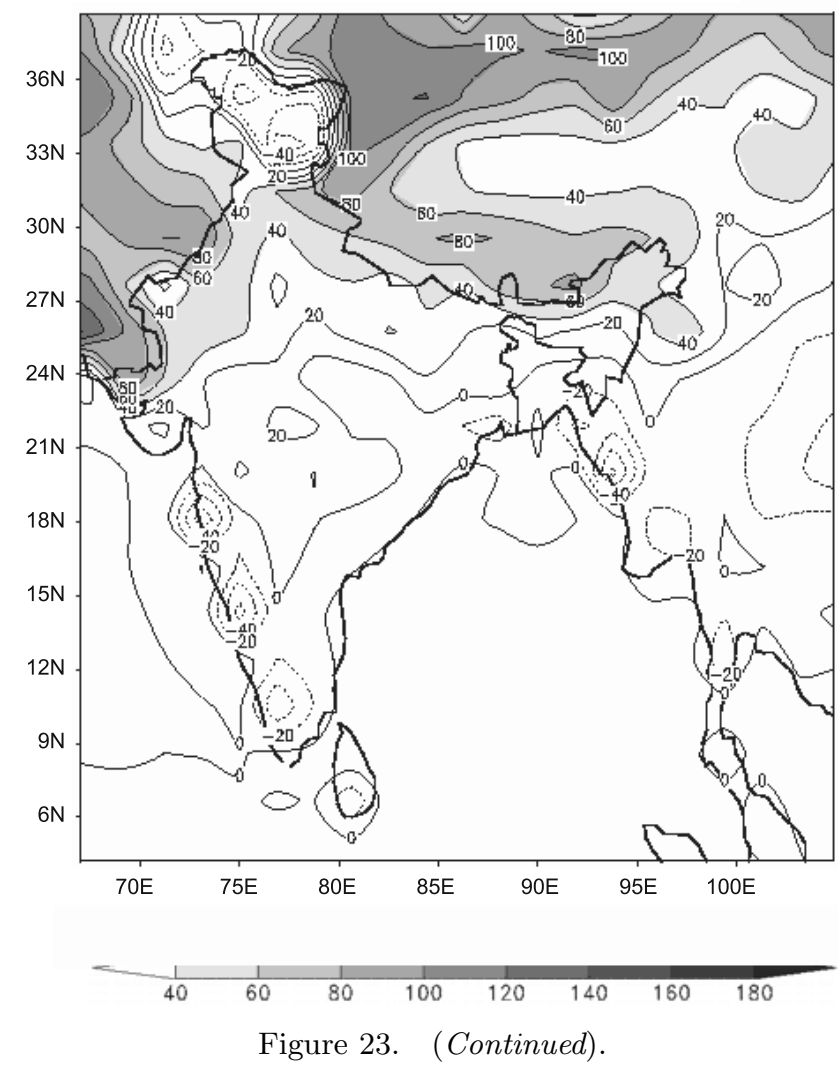

significant changes in the surface parameters (temperature and moisture at $2 \mathrm{~m}$ above the ground, and the sensible and latent heat fluxes). The $2 \mathrm{~m}$ air temperature is better simulated by MM5-ISRO over the northeastern India, showing greater spatial variability over the region. Over northwest India, the sensible heat flux simulated by the MM5USGS is closer to the verification analysis.

Results obtained by Baidya Roy et al (2003) for the US summer climate indicated that land cover changes can impact local precipitation, but not as significantly as it affects temperature, because US summer rainfall is not largely dependent on local land cover and evapo-transpiration. The effects of land cover changes on temperature are significant because the farmlands tend to create lower temperatures through increased evaporation than compared to the grasslands, while croplands are less efficient in transpiration than compared to forest. Both have changed significantly in US since 1700. In the present study, the impact of vegetation over the precipitation and wind fields is found to be more than that over the surface parameters. These studies highlight that the summer rainfall mechanism over US and India and its dependency over land cover and vegetation fractions are not the same.

The present study using USGS and ISRO generated vegetation fraction was made with the 
presumption that the vegetation representing the true state will have positive impact over the southwest monsoon of Indian landmass. The impact of vegetation (irrespective of good or bad) is noticeable from the difference in the MM5 simulated results using USGS and ISRO generated vegetation

Sensible Heat Flux - July, 2002

(a)
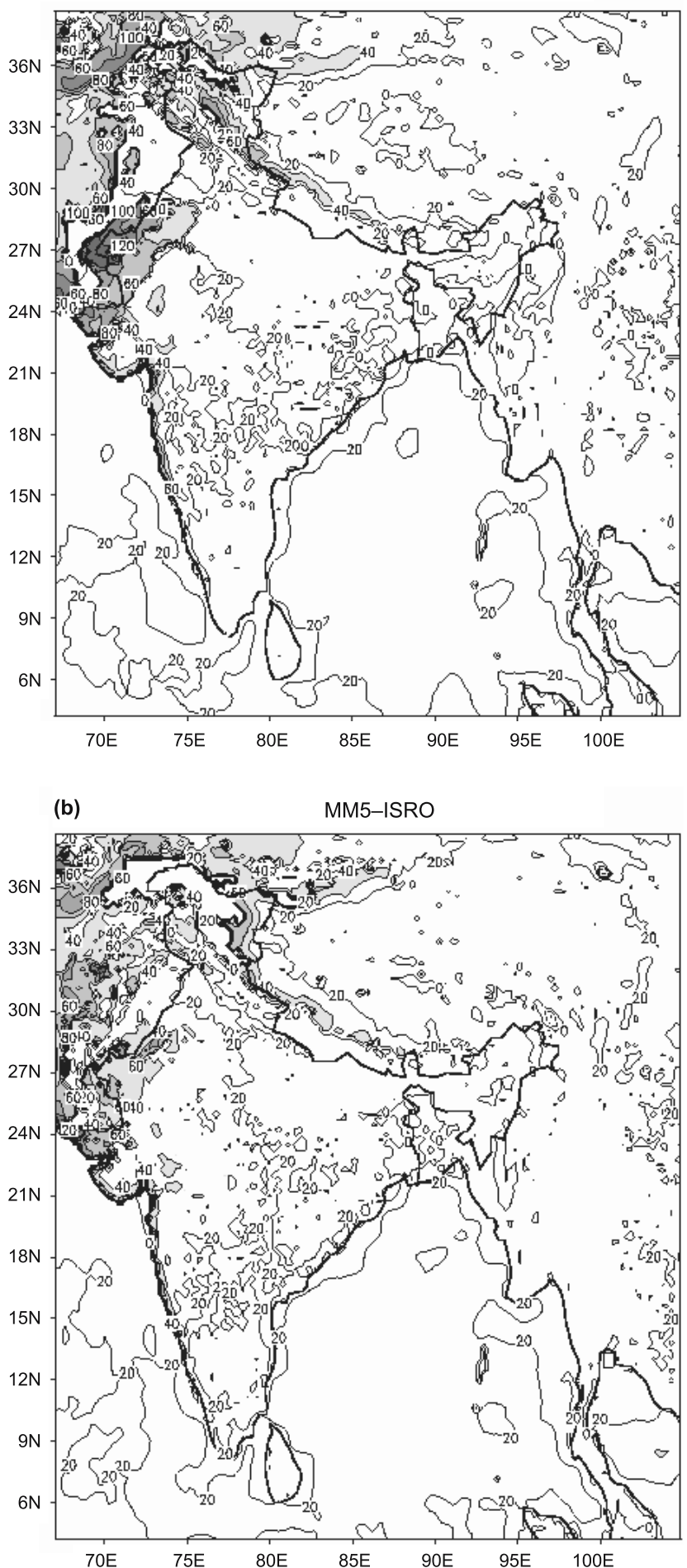

Figure 24. As in figure 23, but for July 2002. (c) NCEP REANALYSIS-II

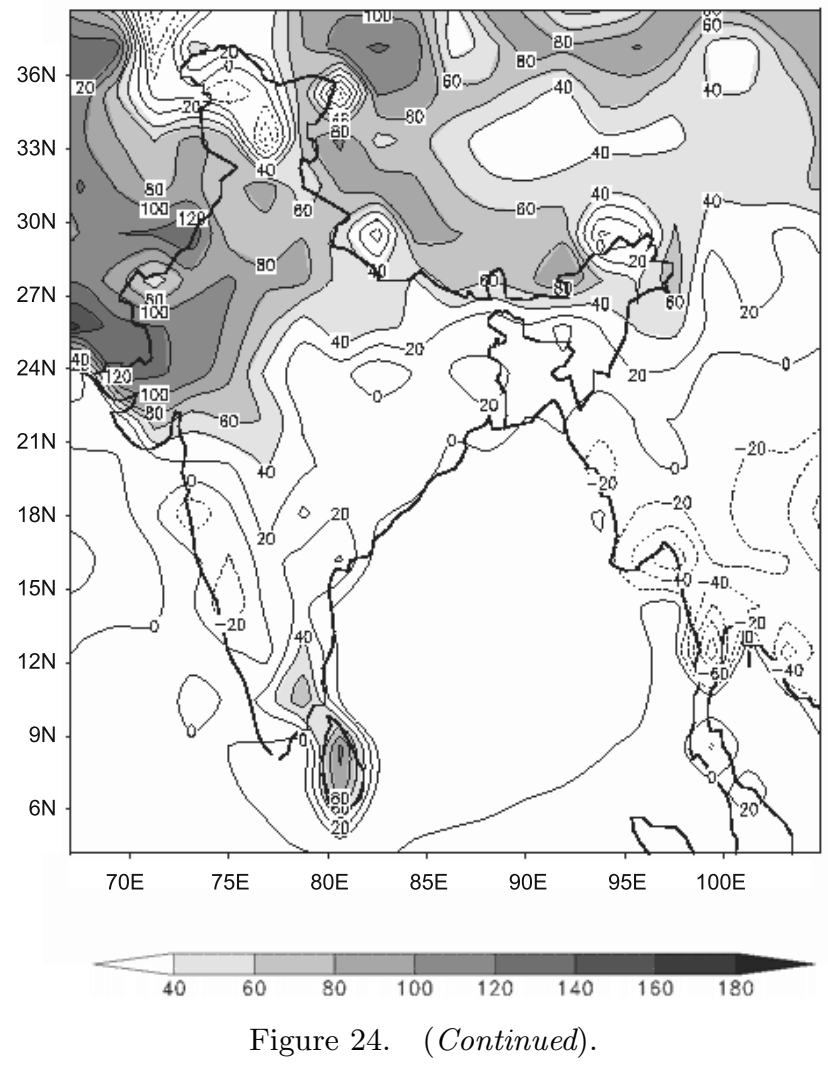

fraction. The main problem in the present MM5 outputs is that the west coast rainfall maxima are shifted to the Arabian Sea, causing significant differences between the observed and simulated rainfall. This could be the probable reason of the overestimation of rainfall over Arabian Sea.

The only difference in the two setups of experiments is the different vegetation fraction. The rest remains completely same for the two. So, the difference in the outputs is solely due to the difference in the vegetation fractions. The positive impact can be regarded to the positive response of the model to the vegetation fraction over the said region and time.

Here, the impact of ISRO vegetation is clearly visible, but persistence and nature of the impact is yet to be studied in detail. It is difficult to conclude the superiority of vegetation fraction between the USGS and ISRO datasets. The results are not the same always for all the seven demarcated regions within the Indian subcontinent. Individually over the smaller regions, USGS does not always score better over ISRO. For probing the impact of vegetation datasets over the Indian region, intensive study is required over smaller regions separately. The difference in vegetation fraction over the regions among USGS and ISRO along with the variation in the type of vegetation and their respective coverage over month and years 
has to be studied. Error incorporated in the SPOT satellite data itself may be one of the reasons. Error might also get incorporated during the process of retrieval.

\section{Acknowledgements}

The research work carried out in this paper was funded by ISRO (Indian Space Research Organization) under the ISRO-GBP (Geosphere, Biosphere Program). The work has been conducted through collaboration between the National Centre for Medium Range Weather Forecasting (NCMRWF), Indian Institute of Technology, Delhi and Space Application Centre, Ahmedabad. Thanks are due to many colleagues who have contributed to the success of this project. First of all, the efforts by Drs V K Dadhwal and Shefali Agrawal of Indian Institute of Remote Sensing, Dehradun are gratefully appreciated for generating the vegetation fraction over the Indian region. Thanks are due to Drs P K Pal and Ranjit Singh of SAC for making the data available in readable format for input to the model. The rainfall data for verification of results were obtained from the NASA's TRMM website. We thank the India Meteorological Department, in particular Dr M Rajeevan for providing the grided rainfall data over the Indian region. We gratefully acknowledge the National Centre for Atmospheric Research (NCAR), USA for their community services and making the MM5 model available. We thank the Head, NCMRWF for his support and making the facilities available to carry out this research at NCMRWF. We would like to thank the two anonymous referees for their valuable comments, which have helped in improving the quality of the manuscript. Last but not the least, we thank Mr Trilochan Pattanaik for plotting the vegetation fraction diagram of USGS and ISRO generated vegetation over the Indian region.

\section{References}

Baldi M, Dalu G A and Pielke Sr R A 2008 Vertical velocities and available potential energy generated by landscape variability - Theory; J. Appl. Meteor. Climatol. 47 397-410.

Basu S, Iyengar G R and Mitra A K 2002 Impact of nonlocal closure scheme in simulation of Monsoon system over India; Mon. Wea. Rev. 130(1) 161-170.

Betts A K, Ball J H, Beljaars A C M, Miller M J and Viterbo P A 1996 The land surface-atmosphere interaction: A review based on observational and global modeling perspectives; J. Geophys. Res. 101(D3) 7209-7225.

Das Someshwar, Surya K Dutta, Kar S C, Mohanty U C and Joshi P C 2007 Impact of vegetation and downscaling on simulation of the Indian summer monsoon using a regional climate model; NCMRWF-IIT Delhi Joint Research Report, 226 pp.
Grell G A, Dudhia J and Stauffer D R 1994 A description of the fifth-generation Penn State/NCAR mesoscale model (MM5); NCAR Technical Note, NCAR/TN-398+STR 1994: 117.

Hoffmann W A and Jackson R B 2000 Vegetation climate feedbacks in the conversion of tropical savanna to grassland; J. Climate 13 1593-1602.

John P George and Begum Z N 1997 Impact of different radiation transfer parameterization schemes in a GCM on the simulation of the onset phase of Indian summer monsoon; Atmosfera 10 1-22.

Kanamitsu M, Alpert J C, Campana K A, Caplan P M, Deaven D G, Iredell M, Katz B, Pan H-L, Sela J and White G H 1991 Recent changes implemented into the global forecast system at NMC; Wea. Forecasting 6 425-435.

Kanamitsu M, Ebisuzaki W, Woollen J, Yang S-K, Hnilo J J, Fiorino M and Potter G L 2002 NCEP-DOE AMIP-II Reanalysis (R-2); Bull. Atmos. Meteor. Soc. 83 1631-1643.

Kar S C, Iyengar G R, Das S, Swati Basu, George J P and Mitra A K 2002 Improvements in the NCMRWF global atmospheric modeling system, Weather and Climate Modeling (eds) Singh, Basu and Krishnamurti, New Age International Publishers, 1.15-1.23.

Kar S C 2007 Global model simulations of inter-annual variability of the Indian Summer Monsoon using observed SST variability; NCMRWF Research Report, $35 \mathrm{pp}$.

Kar S C 1990 Influence of vegetation cover in the ECMWF global spectral model; In: Physical Processes in Atmospheric Models (eds) Sikka D R and Singh S S, Proc. of Indo-US seminar on Physical processes held at IITM, Pune, 1990 pp. 525-536.

Lau K-M and Bua W 1998 Mechanisms of monsoonsouthern oscillation coupling: Insights from GCM experiments; Climate Dyn. 14 759-779.

Lean J and Warrilow D A 1989 Simulation of the regional climatic impact of Amazon deforestation; Nature 342 411-413.

Leung L R, Kuo Y H and Tribbia J 2006 Research needs and directions of regional climate modeling using WRF and CCSM; Bull. Am. Meteor. Soc. 87(12) 1747-1751.

Lim Y-K, Cai M, Kalnay E and Zhou L 2008 Impact of vegetation types on surface temperature change; J. Appl. Meteor. Climatol. 47 411-424.

Liu Hui and Wu Guoxiong 1997 Impacts of land surface on climate of July and onset of summer monsoon A study with an AGCM plus SSiB; Adv. Atmos. Sci. 14 289-308.

Lu Shihua and Chen Yuchun 1999 The influence of northwest China afforestation on regional climate in China; Plateau Meteorology 18 416-424 (in Chinese).

Mabuchi K, Sato Y and Kida H 2005 Climatic impact of vegetation change in the Asian Tropical Region. Part I: Case of the Northern Hemisphere summer; J. Climate 18 410-428.

Meehl G A 1994 Influence of the land surface in the Asian summer monsoon: External versus internal feedbacks; J. Climate 7 1033-1049.

Norbe C A, Sellers P J and Shukla J 1991 Amazonian deforestation and regional climate change; J. Climate 4 957-988.

Nobre P, Moura A D and Sun L 2001 Dynamical downscaling of seasonal climate prediction over Nordeste Brazil with ECHAM3 and NCEP's regional spectral models at IRI; Bull. Am. Meteor. Soc. 82 2787-2796.

Oleson K W, Bonan G B, Feddema J, Vertenstein M and Grimmond C S B 2008 An urban parameterization for a global climate model. Part I: Formulation and evaluation for two cities; J. Appl. Meteor. Climatol. 47 1038-1060. 
Oza S R, Singh R P and Dadhwal V K 2006 Characterization of vegetation fraction estimated using SPOTVEGETATION NDVI data for regional climate modeling in India; Mausam 57 669-674.

Rao D, Bhaskar V, Karumuri Ashok and Toshio Yamagata 2004 A numerical simulation study of the Indian Summer Monsoon of 1994 using NCAR MM5; J. Meteor. Soc. Japan 82(6) 1755-1775.

Rowell D and Blondin C 1990 The influence of soil wetness distribution on short-range rainfall forecasting in the West African Sahel; Quart. J. Roy Meteor. Soc. 116 $1471-1485$.

Sarkar, Sudipta and Menas Kafatos 2004 Interannual variability of vegetation over the Indian sub-continent and its relation to the different meteorological parameters; Remote Sensing of Environment 90 268-280.

Sellars P J and Coauthors 1996 A revised land surface parameterization (Sib2) for atmospheric GCMs, Part I, Model formulations; J. Climate 9 676-705.

Shefali A, Joshi P K, Shukla Y and Roy P S 2003 SPOT vegetation multi temporal data for classifying vegetation in south central India; Curr. Sci. 84(11) $1440-1448$.

Sun Lan, Wu Guoxiong and Sun Shufen 2001 Numerical simulations of land surface processes on climate implementation of $\mathrm{SSiB}$ in IAP/LASG AGCM and its performance; Acta Meteorologica Sinica 15(2) 160-177.

Vinodkumar, Chandrasekar A, Alapaty K and Niyogi D 2008 The impacts of indirect soil moisture assimilation and direct surface temperature and humidity assimilation on a mesoscale model simulation of an Indian monsoon depression; J. Appl. Meteor. Climatol. 47 1393-1412.

Webster P J, Magana V, Palmer T N, Shukla J, Tomas R A, Yanai M and Yasunari T 1998 Monsoons: Processes, predictability, and the prospects for prediction; J. Geophys. Res. 103(C7) 14451-14510.
Weiping L I and Yongkang X U E 2005 Numerical simulation of the impact of vegetation index on the inter-annual variation of summer precipitation in the Yellow River basin; Adv. Atmos. Sci. 22(6) 865-876.

Wu Guoxiong, Sun Lan, Liu Yimin, Liu Hui, Sun Shufen and Li Weiping 2002 Impacts of land surface processes on summer climate; Selected Papers of the Fourth Conference on East Asia and Western Pacific Meteorology and Climate (eds) Chang C-P et al, World Scientific, Singapore, $64-76$.

Xue Y, Fennessy M and Sellers P 1996 Impact of vegetation properties on US Summer Weather Prediction. 41pp. Final Published Version: J. Geophys. Res. 101(D3) 7419-7430.

Xue Y 1997 Biosphere feedback on regional climate in tropical North Africa; Quart. J. Roy. Meteor. Soc. 123B 1483-1515.

Xue Y, Juang H-M H, Li W-P, Prince S, De-Fries R, Jiao Y and Vasic R 2004 Role of land surface processes in monsoon development: East Asia and West Africa; J. Geophys. Res. 109 D03105, doi: 10.1029/2003JD003556.

Yang S and Lau K-M 1998 Influences of sea surface temperature and ground wetness on Asian summer monsoon; J. Climate 11 3230-3246.

Zeng N, Neelin J D, Lau K M and Tucker C J 1999 Enhancement of interdecadal climate variability in the Sahel by vegetation interaction; Science 286 1537-1540.

Zeng Ning and Neelin J D 2000 The role of vegetation climate interaction and interannual variability in shaping the African savanna; J. Climate 13 2665-2670.

Zeng Qingcun, Dai Yongjiu and Xue Feng 1998 Simulation of the Asian Monsoon by IAP AGCM Coupled with an Advanced Land Surface Model (IAP94); Adv. Atmos. Sci. $151-16$.

Zheng Yiqun, Qian Yongfu, Miao Manqian, Yu Ge, Kong Yushou and Zhang Donghua 2002 The effects of vegetation change on regional climate I: Simulation results; Acta Meteorologica Sinica 60 1-16 (in Chinese). 